\title{
Analytical Modeling and Structural Response of a Stretched-Membrane Reflective Module
}

L. M. Murphy (SERI)

D. V. Sallis (Dan-Ka Products)

June 1984

Prepared under Task No. 5102.31

FTP No. 463

Solar Energy Research Institute

A Division of Mid west Research Institute

1617 Cole Boulevard

Golden, Colorado 80401

Prepared for the

U.S. Department of Energy

Contract No. DE-AC02-83CH10093 


\section{PREFACE}

The work presented in this report is part of an ongoing DOE-sponsored research effort to significantly improve the cost and performance of solar thermal concentrators by the development of innovative collector concepts. Prior DOEsponsored research has established the dramatic potential benefit's of the stretched membrane concept. These benefits are due to the structurally efficient design, low weight, simple configuration, likely ease of fabrication, and potentially good optical quality. Our work is directed at increasing our understanding of the structural and optical performance of the coupled membrane/frame problem so that we can ultimately develop an optimal stretchedmembrane heliostat that can realize the full cost and performance benefits of this concept. This work was performed for the U.S. Department of Energy under the general guidance of Frank Wilkins and Martin Scheve of the Division of Solar Thermal Technology.

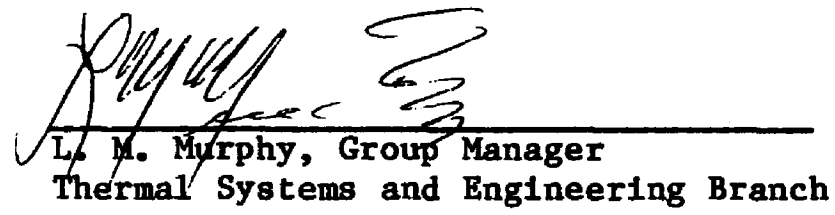

Approved for

SOLAR ENERGY RESEARCH INSTITUTE

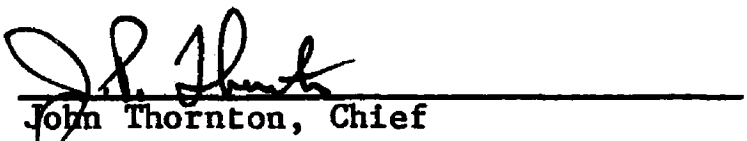

Thermal Systems and Engineering Branch

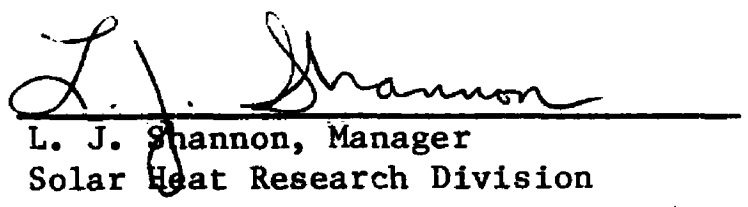




\section{SUMAARY}

\section{Objective}

To describe and develop an understanding of the optical and structural load deformation behavior of a uniform pressure-loaded, stretched-membrane, reflective module subject to nonaxisymmetric support constraints.

\section{Discussion}

To aid in understanding the reflective module behavior, an idealized analytical predictive model was developed and implemented. The stretchedmembrane, reflective module is the major element of the innovative lightweight, and potentially low-cost, heliostat concept that is currently under development. The model is used to study the membrane/frame interactions and deformation process. This report studies the responses of the membrane/frame combination to variations in pressure and tension. It describes the variations of applied lateral shear load, frame lateral deflection, and frame twist as a function of distance between the supports. The accuracy of the results is confirmed with the NASTRAN structural computer code. The Nastran code is also used to provide more detailed insight on specific aspects of the deformation process and to help establish the limits of applicability of the simple model. A simple optical surface error model is also developed and applied to translate frame and membrane surface deformations into quantifiable optical accuracy measures for the assembly. This report focuses on a reflective module with a single structural membrane.

The pertinent structural deformation phenomena of the stretched-membrane reflector studied and presented in this report are intended ultimately to help in the optimization of the design of the stretched-membrane concept, to establish appropriate design criteria for this concept, and to aid potential developers of this concept.

\section{Results and Conclusions}

The analysis demonstrates the need to consider the coupled problem rather than the independent assessment of the frame or membrane. The findings of this analysis indicate that

- The membrane tension can significantly amplify out-of-plane lateral frame deformations relative to an uncompressed, laterally loaded frame. This amplification effect, which increases lateral frame deformation nonlinearly with tension, can also magnify initial frame imperfections due to manufacturing tolerances. However, for a given tension level this amplification effect is constant, resulting in linear deformation increases as the lateral load and initial imperfections are increased.

- The twist/lateral deflection coupling of the frame is significant and, depending on membrane attachment approach and design, requires a careful trade-off between torsional stiffness and bending stiffness to minimize lateral frame deformation and hence the associated optical inaccuracies. 
- If the membrane is attached to the frame, so that its plane does not pass through the frame shear center, an initial twist of the frame will be present prior to lateral pressure loading. This initial twist can amplify out-of-plane deformations and can induce a peak bending stress in the frame that is up to three times as great as the average compressive stress.

- For the range of tensions corresponding to single-membrane designs anticipated for commercial use, the axisymmetric sag of the membrane due to wind-induced pressure loading leads to significantly more optical error than the effect due to nonsymmetric membrane deformations. These nonsymmetric surface deformations are caused by perfodic support constraints and are usually similar to a "scalloped" effect. The axisymmetric effect, however, can be almost totally eliminated by using dual membranes with active pressure and vacuum controls interposed between the membranes.

- Membrane attachment procedures can have a significant impact on the reflective module. Thus if the membrane is rigidly attached to the frame such that it complements the frame-bending stiffness, lateral frame deformation can be reduced by $30 \%$ in some cases and possibly more in cases of large membrane stiffnesses. 
TABLE OF CONTENTS

Page

Nomenclature.......................................... ix

1.0 Introduction...................................... 1

2.0 Model Assumptions..................................... 4

3.0 Frame Equilibrium................................... 7

4.0 Membrane Equilibrium and Corresponding Solution............... 9

5.0 Solution of the Coupled Frame and Membrane Equations............ 12

6.0 Surface Error Mode1.................................. 13

7.0 Results......................................... 15

8.0 Conclusions....................................... 28

9.0 References....................................... 30

Appendix A Frame Equilibrium Equations...................... 32

Appendix B Numerical Solution Approach........................ 36

Appendix $C$ Initial State of a Prestressed Perfect Ring............. 39 
LIST OF FIGURES

Page

2-1 Idealized Stretched-Membrane Reflective Module................

2-2 Frame and Membrane Cross-Section Details......................

4-1 Axisymmetric and Nonsymmetric Deformation Patterns Caused by Lateral Loading and Support Constraints...................... 9

7-1 Maximum Vertical Displacement of the Ring Frame Midway between the Supports as a Function of Applied Lateral Pressure for Several Different Membrane Tensions.......................... 16

7-2 Maximum Vertical Displacement of the Ring Frame Midway between the Supports as a Function of Membrane Tension for Several Applied Lateral Pressures...............................

7-3 The Vertical Load Applied to the Frame by the Membrane at the Attachment Point as a Function of Circumferential Angle $\theta \ldots . . . .$.

7-4 Vertical Displacement of the Frame, Frame Rotation, and Membrane Slope at the Attachment Point, A1l as a Function of the Circumferential Coordinate $\theta \ldots \ldots \ldots \ldots \ldots \ldots \ldots \ldots \ldots \ldots \ldots \ldots \ldots \ldots \ldots \ldots \ldots \ldots \ldots$

7-5 The Bending and Twisting Moment on the Frame Resulting from the Out-of-Pressure Loading on the Membrane as a Function of

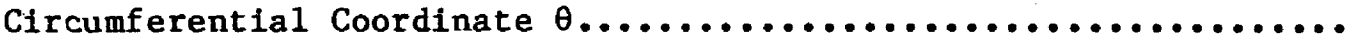

7-6 Vertical Frame Shear Resultant as a Function of Circumferential

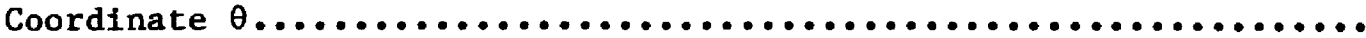

7-7 Normal Membrane Deformation $w$ as a Function of the Circumferential Coordinate $\theta$ for Several Values of the Radius $\ldots \ldots \ldots \ldots \ldots \ldots \ldots$

7-8 Normal Membrane Deformation $w$ as a Function of Radial Distance from the Membrane Center for Two Values of $\theta \ldots \ldots \ldots \ldots \ldots \ldots \ldots \ldots \ldots \ldots \ldots \ldots$

7-9 The Ratio of RMS Surface Errors $\left(\beta_{2} / \beta_{1}\right)$ as a Function of Tension in the Membrane................................ 23

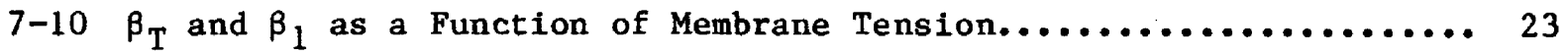

7-11 Effect of Torsional Rigidity on Vertical Displacement Frame....... 26

A-1 Equilibrium Forces on an Incremental Element of the Frame........ 32

A-2 A Circumferential View of the Frame Cross Section and the Rotation Angle of the Frame as Well as the Relative Rotation of the Membrane to the Frame and the Horizontal................ 


\section{TABLE}

Page

C-1 Initial Stresses and Displacements in an Initially Perfect Frame.......................................... 39 


\section{NOMENCLATURE}

a

A

$\mathbf{A}_{\mathbf{n}}$

B

D

$\mathrm{D}_{i j}$

E

$f(\theta)$

G

h

H

$\mathrm{I}_{\mathrm{y}}$

K

My

$\mathrm{M}_{\mathrm{Z}}$

$\mathrm{N}$

P

Q

R

$\mathbf{r}$

s

$\mathrm{T}_{\mathrm{O}}$

u

V

v

W

w

$w_{1}$

$w_{2}$

$w_{0}$

radius of membrane (m)

area of frame eross seetion $\left(\mathrm{m}^{2}\right)$

$\mathrm{n}^{\text {th }}$ Fourier eoeffielent for membrane defleetion solution numerieal eorreetion matrix defined in Appendix B

displacement matrix defined in Appendix $B$

eomponents of displaeement matrix D

Young's modulus for frame material ( $\mathrm{Pa})$

total vertieal displaeement of membrane attaehment interfaee on the ring/frame $=v(\theta)+\rho \phi(\theta)(m)$

shear modulus for frame material (Pa)

vertieal distanee above the plane of the frame eentroid, from whieh the membrane is mounted (m)

half height of frame eross seetion (m)

a feal moment of inertia about the $y$ axis of the frame eross seetion $\left(\mathrm{m}^{4}\right)$

torsional constant of the frame eross seetion $\left(\mathrm{m}^{4}\right)$

loeal bending moment about $y$ axis of frame $(N \cdot m)$

loeal twist moment about $z$ axis of frame $(\mathrm{N} \bullet \mathrm{m})$

ring compression load (N)

uniform pressure on membrane ( $\mathrm{Pa}$ )

vertieal load per unit length applied to the frame $(\mathrm{N} / \mathrm{m})$

$(a+\rho)$ radius to centerline of frame (m)

radial eoordinate (m)

displaeement veetor defined in Appendix B

initial tension in membrane $(\mathrm{N} / \mathrm{m})$

radial frame displaeement (m)

frame shear resultant (N)

out-of-plane vertieal ring deformation (m)

half-width of frame seetion (m)

membrane deformation, normal to the surfaee, in the vertieal direetion (m)

axisymmetrie eomponent of $w$ (m)

nonaxisymmetrie eomponent of $w(m)$

eenter deformation of edge-fixed, uniformly loaded membrane (m) 
$\overrightarrow{\mathrm{Z}}$

$x, y, z \quad$ local coordinates measured from the centroid of an arbitrary circumferential $(\theta)$ frame cross section; $x$ is directed vertically upward and is normal to the membrane plane; $y$ is directed radially outward and is parallel to the membrane plane; $z$ is circumferentially directed (normal to the cross-section plane) in the positive $\theta$ direction

$\alpha$

$=-\left.\frac{\partial w}{\partial r}\right|_{r=a}=\begin{aligned} & \text { angle with which the membrane meets the frame measured } \\ & \text { from the horizontal (rad) }\end{aligned}$

$\beta \quad$ RMS surface slope error (rad)

$\theta$ circumferential coordinate (rad)

$\rho$ radial membrane attachment offset, measured from frame centroid (m)

$\psi \quad$ angular integration variable (rad).

$\vec{\Omega} \quad$ local surface rotation vector for the membrane (rad)

$\phi \quad$ frame twist angle (rad)

$\sigma \quad$ total stress on frame cross section face in $z$ direction ( $\mathrm{Pa}$ )

$\sigma_{\mathrm{ZN}} \quad$ stress on frame cross section face in $z$ direction corresponding to normal compressive load resultant ( $\mathrm{Pa}$ )

$\sigma_{\mathrm{ZB}} \quad$ stress on frame cross section face in $z$ direction corresponding to bending $(\mathrm{Pa})$

( )' a prime superscript denotes differentiation with respect to $\theta$ 


\section{INTRODUCTION}

Tracking collectors, used to concentrate solar radiation for solar thermal applications, aurrently represent the most costly part of solar thermal systems, and there continues to be considerable interest in improving the cost and performance of these components. The stretched-membrane heliostat concept has the potential to significantly improve the cost and performance of heliostat collectors, as has been established by previous DOE-sponsored research [1]. Further, this research has led to the proposal of numerous innovations.* In the stretched-membrane concept, a reflector film-which can be metal, polymeric, or a composite--is stretched on a hollow toroidal frame that offers a structurally efficient design, low weight, a simple configuration, likely ease of fabrication, and a surface of potentially good optical quality. Although stretched-membrane research was intended to improve heliostat concentrator cost and performance for solar thermal applications, the stretched-membrane collector design approach may offer effective cost and performance opportunities for improving photovoltaic and solar daylighting applications as well as by providing a very cost-effective tracking platform.

To realize the potential of this concept, an understanding of the structural response of the membrane-frame combination is needed to help in the optimization of the concept, to establish appropriate design criteria, and to aid potential developers of this concept. Issues such as the deformation of the frame and the membrane, and more importantly the interaction of the frame and membrane, under various pressure (due to wind) and tension loads need to be studied. Idealized or simplified models of conceptual stretched-membrane reflective modules are useful in developing an understanding and a definition of how a stretched-membrane reflector should be formed.

The idealized model considered in this report, a stretched membrane mounted on a stiff support frame that in turn is supported by periodic attachments at equidistant circumferentially spaced points, is of interest relative to the design, evaluation, and optimization of stretched-membrane heliostats, which have been under development for some time [1]. To be of value this idealized problem should model reasonably well the real static deformation and optical accuracy of stretched-membrane reflectors so that the dominant physical phenomena are accurately considered. In the present context, optical accuracy means the degree to which the desired membrane shape (in a macro sense) can be maintained under specified loading conditions. If the deformed surface shape can be predicted then the optical accuracy can be easily quantified by determining the surface slope errors caused by the deformations relative to the desired shape. Once the surface slope exrors are determined, any of a number of surface error measures can be used to quantify an average surface quality.

*At least four patent applications relating to this concept have been filed and one has been granted (i.e., U.S. Patent No. 4,425,904 issued 17 January 1984 to B. Butler). 
An accurate simple model also is useful to size structural members so that the deformations of the support frame/ring and membrane are limited to acceptable levels, especially in the preliminary design effort. Further, such a model can aid in the optimization of the reflector module by permitting the rapid screening of various design approaches. Moreover, the analytical approach enhances the physical understanding of the problem by more readily pinpointing the interaction of various phenomena such as the amplification of frame lateral distortion by the membrane tension. Finally, parametric trade-offs are more easily and cost-effectively performed with the simple model than with large and cumbersome finite element codes such as NASTRAN [2].

Either the membrane or the support frame, when taken individually, represents an easily analyzed structure (from a deformation perspective). For membranes, solutions are readily available for both infinitesimal and large finite deformations [3-6], while for circular structural frames many standard procedures are available. Numerous articles describe the response of these frames to various loading conditions [7-14]. The more general coupled problem, however, has not been studied extensively in the literature, though some related studies have been performed [18].

The nonaxisymmetric deformation problem resulting from periodic support of the frame while under uniform lateral load is significantly more complex than the uniformly supported frame case. The problem is primarily of practical interest because of the structural deformation and optical accuracy issues associated with the stretched-membrane reflector and because the framemembrane assembly represents initially stressed structures subjected to additional incremental deformations.

An understanding of the resulting coupled frame-membrane interaction problem is of interest for the membrane parabolic dish as well as heliostat applications. The frame-membrane combination is also interesting since the membrane and the frame respond in very different ways. For instance, the prestressed (tension) membrane supports the applied load by changing shape (i.e., the deformation is independent of material properties and the thickness of the membrane), and no strains in addition to those induced by the initial tension are induced by lateral loading. Of course with a higher order analysis the membrane experiences additional strains, and the solution depends upon the thickness of the membrane and the elastic properties of the membrame material. The frame, which is also prestressed (in compression due to the membrane tension), deforms so that additional bending- and twisting-induced strains result as the frame-membrane assembly is loaded normal to the plane of the membrane by wind and weight loads.* Further, the frame bending and twisting deformation interact in a complex manner with the membrane and the nearly constant frame compressive load resultants. Small deformation theory can be used here since deformations that are large from an optical accuracy perspective are still relatively small from a strain compatibility and structural viewpoint.

*The plane of the membrane is represented as if it were perfectly flat in the unloaded condition. In actuality, there will always be a slight curvature of the membrane whether caused by a combination of focusing procedures, lateral loading due to wind and weight, or initial imperfections in the membrane-frame assembly. 
The following sections describe the model assumptions in detail and then present the idealized analytical model that approximately describes the load deformation behavior of the stretched membrane. A surface error model is then developed to allow optical characterization of the deformed surface. Following the development, the model is exercised on a typical stretched-membrane reflective module, and the results are confirmed with the NASTRAN [2] structural computer code to verify the assumptions and the applicability of the mode1. The NASTRAN results are also used to help establish more detafled insight into specific aspects of the deformation process. It is noted that ultimately the verification of the model as well as the NASTRAN predictions must be done experimentally; such experiments are being planned by DOE. 
SECTION 2.0

MODEL ASSUMPTIONS

Consider a circular stretched-membrane reflector support frame assembly, as shown in Figures 2-1 and 2-2, and let the following assumptions hold:

- The toroidal membrane support frame of mean radius $R$ is supported vertically at three equidistant points around the circumference. These constraints approximate the reactions of a tripod support strut arrangement similar to that found in some heliostat designs [1].

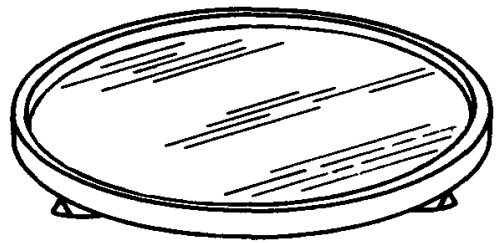

(a) Perspective view - stretched-membrane reflective module; pin supported at three equidistant circumferential points

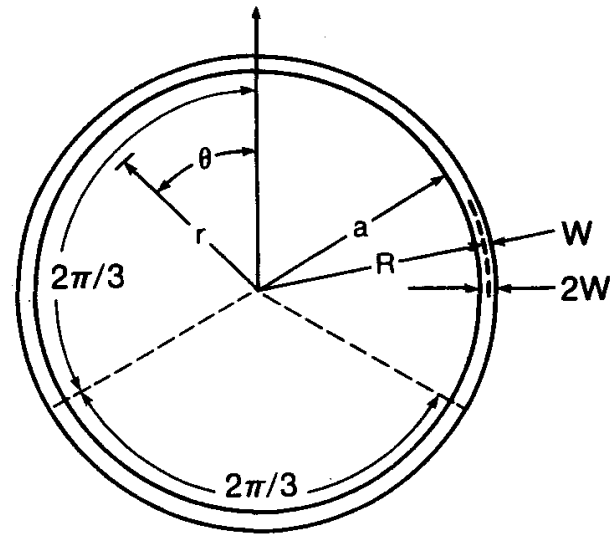

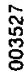

(b) Top view - stretched-membrane reflective module

Figure 2-1. Idealized Stretched-Hembrane Reflective Module 


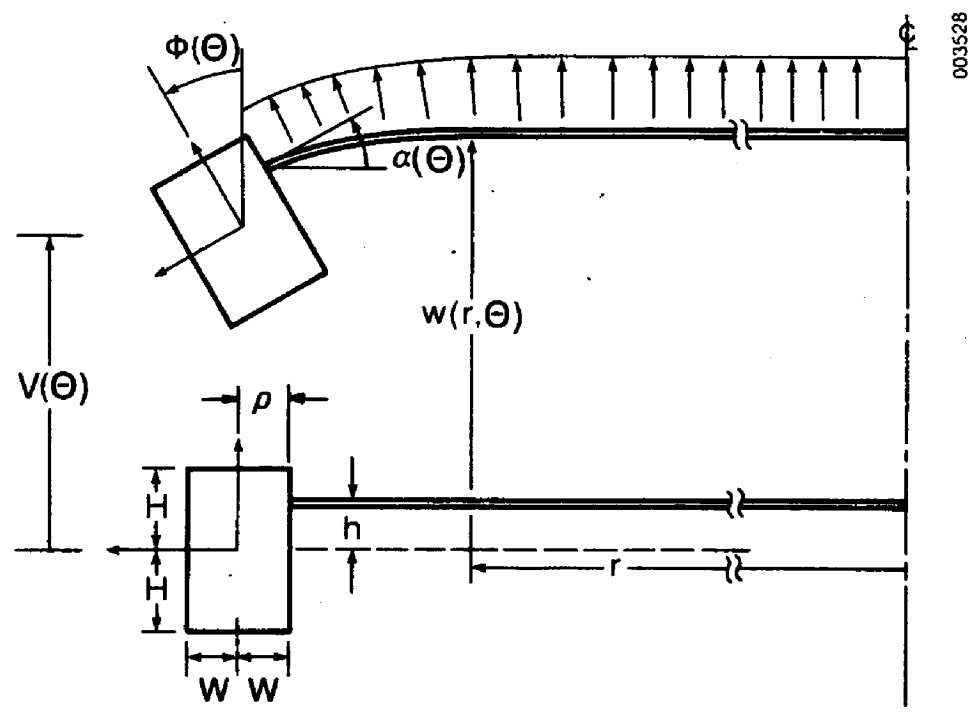

(a) Frame and cross-section detail showing displacements and the corresponding directions and applied loading

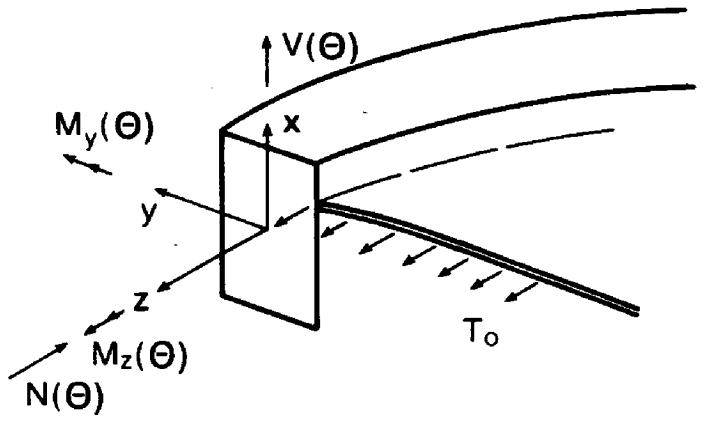

(b) Perspective of trame and membrane cross section showing internal load resultants and local coordinates

Figure 2-2. Frane and Membrane Cross-Seetion Details

- The supports offer only a vertieal (i.e., perpendieular to the plane of the membrane) eonstraint; i.e., the frame is free to rotate at the supports but not to translate vertieally or laterally in the radial direetion.

- Small deformation theory is assumed for both the frame and membrane.

- The membrane earries loads only in tension (no bending eapability) everywhere ineluding the region near the attaehment. The tensions are assumed to be eonstant and large enough that the deformations do not lead to signifieant variations in the tension loads over the surface. Furthermore, only membrane deformations normal to the surface 
are considered, and the membrane is assumed to be loaded normally and uniformly.

- Only out-of-plane deformation and twist of the ring are considered (radial shear and radial ring deformations are ignored). Circumferentially compressive loads in the support frame are important as are the normally considered twist, vertical shear, and moment resultants. The coupling of the out-of-plane deformation with the ringcompressive force must be considered, but the ring compression load is assumed to remain constant around the circumference in all cases.

- The principle of linear superposition is assumed to be valid for both the deformation and the stress state in the frame and membrane. Thus deformations and stresses caused by the lateral pressure load on the membrane are superimposed on the initial prestressed and prestrained state implied by the initial membrane tension state.

- The frame cross section is rectangular, with external width $2 \mathrm{~W}$ and height $2 \mathrm{H}$, and is uniform around the circumference; wall thickness is arbitrary.*

- Displacement compatibility of the membrane at the support frame interface attachment is required.

- The model presented in the main body of this report is derived for a single membrane that forms a plane (of a height $h$ vertically above the plane) that in turn passes through the centroid of the toroidal frame. This model simplifies the presentation, but generalizations to allow multiple membranes, each with different loadings, are easily incorporated and are presented in Appendix $A$. The model also assumes a horizontal offset, from the frame centroid, of magnitude $\rho$ (in Figure 2-2 $\rho$ is shown equal to $W$ but it need not be).

*The model we developed is valid for any symmetric cross section; care must be taken to properly define the attachment dimensions. Nonsymmetric cross sections with products of inertia other than zero lead to more coupling terms than appear in the equations below. 
SECTION 3.0

FRAME EQUILIBRIUM

Let the membrane of radius a have a tension $T_{0}$ and let the deformation of the frame be described by the lateral displacement $v(\theta)$ and twist $\phi(\theta)$ with the directions shown in Figure 2-2. Further, let the slope of the membrane, relative to the horizontal, at the frame attachment be given by $\alpha(\theta)$. The local moment equilibrium equations in the $y$ and $z$ directions are then described, from the presentation in Appendix A, by:

$$
\frac{\partial^{2} M_{y}}{\partial \theta^{2}}-\frac{\partial M_{z}}{\partial \theta}-\operatorname{RaT}_{0}\left(\alpha-\frac{1}{R} \frac{\partial^{2} v}{\partial \theta^{2}}\right)=0,
$$

and

$$
\frac{\partial M_{z}}{\partial \theta}+M_{y}-a T_{o}(\phi-\alpha) \rho=0,
$$

respectively, where $M_{y}$ and $M_{z}$ are the local bending and twist moments, respectively, about the frame centroid at the section defined by the angle $\theta$ (see Figure 2-2). The horizontal membrane attachment of $f$ set $\rho$ is also measured from the centroid $(\rho=W$ in Figure 2-2).

It is important to note that the displacements $v$ and $\phi$ described here, as well as $M_{y}$ and $M_{z}$, are the increments caused by the lateral load on the membrane. We assume that these are added to the values induced by the tensioned membrane during assembly. Appendix $C$ describes initial displacements and loads in the ring for an initially perfect ring after application of the membrane.

Here, as noted earlier, $h$ is the vertical distance above the plane formed by the frame centroid from which the membrane is mounted. Thus, a nonzero $h$ will result in a constant initial twist (due to the initial membrane tension $T_{0}$ ) in the frame even when no lateral loading of the frame is considered. Appendix A presents the derivation of these coupled moment equilibrium equations. However, it is instructive to note the physical significance of the last-term grouping in Eqs. 2-1 and 2-2. The last grouping to the right in Eq. 2-2 represents the applied local twist about the $z$ axis due to the membrane. The last grouping to the right in Eq. 2-1 represents two effects. The term $\alpha$ is a result of the vertical loading caused by the deformed membrane, which in turn results in shear induced out-of-plane bending (as in a beam). The second element in this grouping (involving $\partial^{2} v / \partial \theta^{2}$ results from the moment about the local $y$ axis caused by the ring compression $N(\theta)$ (see Figure 2-2), which in turn is induced by the membrane tension. This last effect is analogous to the effect of an axial compressive force on a laterally loaded straight beam.

$M_{y}$ can be described in terms of the displacements and the frame flexural rigidity $\mathrm{EI}_{\mathrm{y}}$ by the bending moment curvature change relationships $[15,16]$ :

$$
M_{y}=\frac{E I_{y}}{R}\left[\frac{1}{R} \frac{\partial^{2} v}{\partial \theta^{2}}-\phi\right]
$$


Likewise, the corresponding expression for the frame twist $M_{z}$ in terms of the frame torsional rigidity KG and the displacements is [15]

$$
M_{z}=\frac{K G}{R}\left[\frac{\partial \phi}{\partial \theta}+\frac{1}{R} \frac{\partial v}{\partial \theta}\right]
$$

The moments $M_{y}$ and $M_{z}$ can be eliminated by combining Eqs. 2-1 through 2-4, resulting in coupled equations for the displacements corresponding to the twist and bending of the support frame. The resulting displacement equilibrium equations are

$$
\frac{E I_{y}}{R}\left[\frac{1}{R} v^{\prime} \cdot '-\phi^{\prime \prime}\right]-\frac{G K}{R}\left[\phi^{\prime \prime}+\frac{1}{R} v^{\prime \prime}\right]-\operatorname{RaT}_{o}\left(\alpha-\frac{1}{R} v^{\prime \prime}\right)=0,
$$

for the bending equation and

$$
\frac{G K}{R}\left[\phi^{\prime \prime}+\frac{1}{R} v^{\prime}\right]+\frac{E I_{y}}{R}\left[\frac{v^{\prime \prime}}{R}-\phi\right]-\mathrm{aT}_{0} \rho(\phi-\alpha)=0,
$$

corresponding to the twist equation. Note that the prime superscript denotes simple total differentiation of the quantity with respect to $\theta$.

The corresponding boundary conditions for Eqs. 2-5 and 2-6 are then easily determined from symmetry conditions at the three supports (i.e., $\theta=0,2 \pi / 3$, $4 \pi / 3)$. Hence, from symmetry arguments only one segment of the ring must be considered (i.e., from $\theta=0$ to $\theta=2 \pi / 3$ ). Then the appropriate boundary conditions are

$$
\mathrm{v}(0)=\mathrm{v}\left(\frac{2 \pi}{3}\right)=\mathrm{v}^{\prime}(0)=\mathrm{v}^{\prime}\left(\frac{2 \pi}{3}\right)=\phi^{\prime}(0)=\phi^{\prime}\left(\frac{2 \pi}{3}\right)=0 .
$$




\section{SECTIOI 4.0}

\section{LRMBRANE EQUILIBRIUM AND CORRESPONDILG SOLUTION}

The linear membrane deformation solution for lateral displacement is easily determined from classical analysis. The solution is just the sum of two linear solutions. The first solution corresponds to an axisymmetric problem and is obtained from Poisson's equation with homogeneous boundary conditions. The second linear solution corresponds to the nonaxisymmetric problem where the solution is obtained from Laplace's equation with nonhomogeneous boundary conditions. Physically, the second solution corresponds to a uniformly tensioned membrane, which is unloaded laterally and has a nonzero edge displacement equal to the displacement of the frame (at the attachment point) (see Figure 4-1).

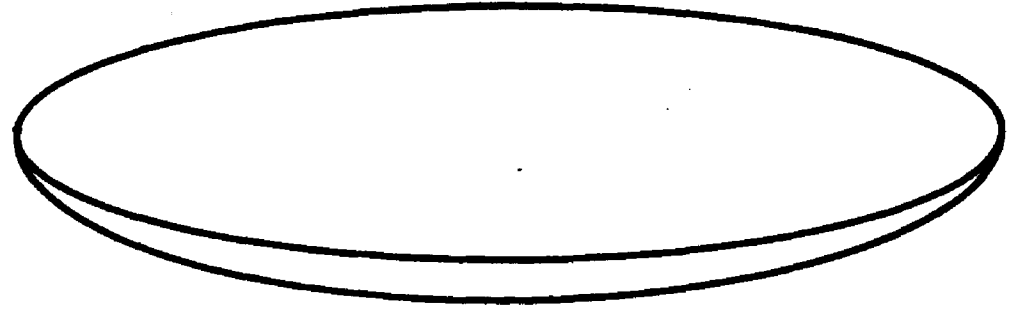

(a) $w_{1}$ axisymmetric portion of membrane deformation

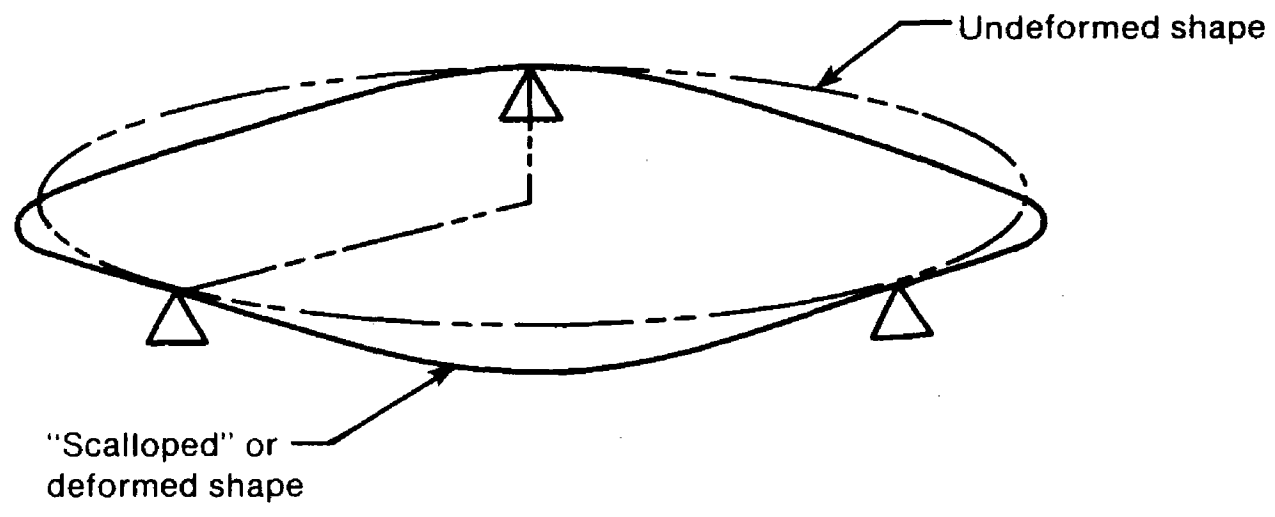

(b) $w_{2}$ nonsymmetric, "scalloped," membrane shape caused by support constraints

Pigure 4-1. Axisymetric and Nonsymetric Deformation Patterns Caused by Lateral Loading and Support Constraints 
Let the two membrane displacement solutions described above be denoted by $\mathrm{w}_{1}$ and $w_{2}$, respectively; then the total displacement $w$ is

$$
\mathrm{w}=\mathrm{w}_{1}+\mathrm{w}_{2},
$$

and the symmetric membrane deformation $w_{1}$ is determined from

$$
\nabla^{2} w_{1}(r, \theta)=-\frac{P}{T_{0}},
$$

with the boundary condition

$$
w_{1}(a, \theta)=0 \text {, }
$$

where $P$ is the uniform pressure applied to the membrane and $T_{0}$ is the initial membrane tension. Furthermore, the nonsymmetric membrane deformation caused by the displacement of the support frame is determined from

$$
\nabla^{2} w_{2}(r, \theta)=0 \text {, }
$$

with the boundary condition

$$
w_{2}(a, \theta)=f(\theta),
$$

where $f(\theta)$ is the vertical displacement of the ring interface attachment. The solution to Eqs. 4-2 and 4-3 is

$$
\mathrm{w}_{1}=\frac{\mathrm{Pa}^{2}}{4 \mathrm{~T}_{\mathrm{o}}}\left[1-\left(\frac{\mathrm{r}}{\mathrm{a}}\right)^{2}\right] \text {, }
$$

and the solution for $w_{2}$ is determined from a simple Fourier analysis given by

$$
w_{2}(r, \theta)=\frac{1}{\pi} \sum_{n=1}^{\infty}\left(\frac{r}{a}\right)^{n} \cos n \theta \int_{0}^{2 \pi}[v(\psi)+\rho \phi(\psi)] \cos n \psi d \psi \text {, }
$$

where it is noted that the compatibility relation for the membrane displacement at the frame attachment is used in the Fourier coefficient integral and is given by

$$
w_{2}(a, \theta)=w(a, \theta)=v(\theta)+\rho \phi(\theta)=f(\theta) .
$$

Thus, the total solution for $w$ is determined as in Eq. 4-1 and is given by

$w(r, \theta)=\frac{P a^{2}}{4 T_{0}}\left[1-\left(\frac{r}{a}\right)^{2}\right]+\frac{1}{\pi} \sum_{n=1}^{\infty}\left(\frac{r}{a}\right)^{n} \cos n \theta \int_{0}^{2 \pi}[v(\psi)+\rho \phi(\psi)] \cos n \phi d \psi \dot{(4-9)}_{(4)}$

Thus, the explicit dependence of the membrane solution on the frame displacement is shown. Further the frame Eqs. $3-5$ and 3-6 depend on $\alpha(\theta)$, which is just the slope of the membrane at the attachment point. That is, $\alpha(\theta)$ is defined by 


$$
\begin{aligned}
\alpha(\theta) & =-\left.\frac{\partial w(r, \theta)}{\partial r}\right|_{r=a} \\
& =\frac{p_{a}}{2 T_{0}}-\frac{1}{\pi a} \sum_{n=1}^{\infty} n \cos n \theta_{0} \int^{2 \pi}[v(\psi)+\rho \phi(\psi)] \cos n \psi d \psi, \quad(4-10)
\end{aligned}
$$

which is found by differentiating Eq. 4-9. 


\section{SECTION 5.0}

\section{SOLUTION OP THE COUPLED FRAME AND MEMBRANE EQUATIONS}

The coupled membrane frame solution can now be obtained by the simultaneous solution of the coupled frame displacement (Eqs. 3-5 and 3-6) and the membrane slope (Eq. 4-10).

We arrive at the simultaneous solution of Eqs. 3-5, 3-6, and 4-10 in the following manner. First, a constant value for $\alpha(\theta)$ is chosen. A good starting value for $\alpha(\theta)$ is the slope corresponding to the axisymmetric solution, which is $\mathrm{Pa} /\left(2 \mathrm{~T}_{0}\right)$ as obtained from Eq. 4-10. Once $\alpha(\theta)$ is known the bending and twist equations (Eqs. 3-5 and 3-6) are solved for $\phi(\theta)$ and $v(\theta)$. The new values for $\phi(\theta)$ and $v(\theta)$ are then substituted into Eq. 4-10, and an updated solution for $\alpha(\theta)$ is determined. The solution for $\alpha(\theta)$ is now substituted back into Eqs. $3-5$ and 3-6, and the process is repeated as before. This iterative process is carried out until the new value and the previous value for $\phi(\theta)$ and $v(\theta)$, as well as $\alpha(\theta)$, do not differ beyond a prescribed inaccuracy limit. In practice, no more than 10 to 12 iterations are required to provide very satisfactory convergence. 
SECTION 6.0

SURPACE ERROR MODEL

The surfaee aeeuraey of the membrane ean be determined from the surfaee deformations by defining surface slope ehanges due to the loading. These surface slope ehanges are determined most easily from the surface rotation vector as defined in elassieal shell theory [17]. For shallow shells, using eylindrieal eoordinates, and negleeting rotations about the normal surface direetions (sinee this rotation eomponent will not lead to optieal errors), the surfaee rotation vector $\bar{Q}$ ean be defined to first order by

$$
\vec{z}=\frac{\partial w}{\partial \mathbf{r}} \overrightarrow{\mathbf{e}}_{\theta}+\frac{1}{\mathbf{r}}\left(\frac{\partial w}{\partial \theta}\right) \overrightarrow{\mathbf{e}}_{\mathbf{r}},
$$

where $\vec{e}_{\theta}$ and $\vec{e}_{\mathbf{r}}$ are the unit base veetors in the $\theta$ and $r$ direetions, respeetively. Having determined the surfaee rotation veetor, the slope error and surfaee aceuraey are easily found. The most eommon surfaee error measure [19] used to define optieal aeeuraey for refleetors is the root-mean-square (RMS) average of the surface rotation $d$. Using the RMS average definition, $\beta$ ean be desertbed by

$$
\beta=\left\{\frac{s_{s}^{\int} \partial \cdot \vec{\alpha} \mathrm{dA}_{\mathbf{s}}}{\mathrm{dA}_{\mathrm{s}}}\right\}^{1 / 2}
$$

where the surface area element $\mathrm{dA}_{s}$ is given by

$$
\mathrm{dA}_{\mathbf{s}}=\mathbf{r} \mathrm{dr} d \theta \text {. }
$$

Substituting Eq. 6-1 into Eq. 6-2 results in

and

$$
\beta=\left\{\frac{\delta \iint\left[\left(\frac{\partial w}{\partial r}\right)^{2}+\frac{1}{r^{2}}\left(\frac{\partial w}{\partial \theta}\right)^{2}\right] r d r d \theta}{\int_{s} \int d A}\right\}^{1 / 2},
$$

$$
=\left\{\frac{\int_{0}^{2 \pi} \int_{0}^{a}(\nabla w \cdot \nabla w) r d r d \theta}{\pi a^{2}}\right\}^{1 / 2},
$$

where $\nabla w$ represents the vector gradient of the membrane surface deformation w.

It is important to note that Eq. 6-3 is valid to first order for shallow shells and henee is applieable for slightly eurved or focused membranes as well. The only point to remember is that in Eq. 6-3 w is the inerement in displacement from the equilibrium position of the unloaded membrane. Sueh foeused membranes may be developed by methods as deseribed in Ref. 1.

If we rewrite $\mathrm{Eq} \cdot$ 4-9 in the form

$$
w(r, \theta)=\frac{P a^{2}}{4 T_{0}}\left[1-\left(\frac{r}{a}\right)^{2}\right]+\sum_{n=1}^{\infty} A_{n}\left(\frac{r}{a}\right)^{n} \cos n \theta
$$


where

$$
A_{n}=\frac{1}{\pi} \int_{0}^{2 \pi}[v(\psi)-\rho \phi(\psi)] \cos n \psi d \psi,
$$

then $\beta$ can be rewritten using Eqs. 6-5 and 6-3 and the orthogonality conditions in the $\theta$ integration. $\beta$ can be described by:

$$
\begin{aligned}
\beta & =\left\{\frac{2}{a^{2}}\left(\frac{P^{2}}{4 T_{0}}\right)^{2}+\sum_{n=1}^{\infty} n\left(\frac{A_{n}}{a}\right)^{2}\right\}^{1 / 2} \\
& =\left\{2\left(\frac{w_{0}}{a}\right)^{2}+\sum_{n=1}^{\infty} n\left(\frac{A_{n}}{a}\right)^{2}\right\}^{1 / 2},
\end{aligned}
$$

where $w_{0}$ is the center deflection of a uniformly loaded membrane fixed at the edge $(r=a)$, defined by

$$
\mathrm{w}_{\mathrm{o}}=\frac{\mathrm{Pa}^{2}}{4 \mathrm{~T}_{\mathrm{o}}} \text {. }
$$

Thus, as seen in Eq. 6-6, the surface error has two contributions--one from the axisymmetric uniformly loaded membrane and one from the out-of-plane support frame displacements. For passive surface control (i.e., no active control of the net pressure on the reflective surface) and for a reasonably stiff frame or from a low-membrane pretension $\left(T_{0}\right)$, the error will be dominated by the first term, and therefore $\beta$ can be described by

$$
\beta \simeq \sqrt{2}\left(\frac{w_{0}}{a}\right)
$$

An even better approximation for $\beta$ can be obtained by also considering the maximum vertical deflection between the supports $V_{\max }$, corresponding to the nonaxisymmetric deformation as well as the axisymmetric deformation, which results in

$$
\beta \simeq\left\{2\left(\frac{w_{o}}{a}\right)^{2}+j\left(\frac{v_{\max }}{2 a}\right)^{2}\right\}^{1 / 2},
$$

where $j$ is the number of evenly spaced vertical supports. When the net reflective surface is actively controlled, the first term in Eq. 6-9 can be essentially eliminated. Active control might be implemented in a double membrane design by controlling the vacuum between the two membranes so that the average pressure on the reflective membrane is reduced to zero. 
SECTION 7.0

\section{RESULTS}

As previously noted, the primary purpose of this report is to describe the simple analytical model and demonstrate the major structural response issues corresponding to the stretched membrane-frame combination. An additional aim is to describe the model's characteristics and its potential capability for the design and the prediction of the optical performance of stretched-membrane hellostat reflective modules under pressure loading. Although many insights can be gained into the design of such reflective modules and many meaningful trade-offs can be presented, only a few will be discussed here. Stability investigations, trade-off studies, and parametric variations that show design trends and preferred technical approaches will be presented in later reports.

Figures 7-1 through 7-6 illustrate some of the model characteristics and capabilities. For each of these figures a single-ring configuration is used, which is characterized by the following geometric and structural properties: $\mathrm{R}=5.0 \mathrm{~m}, \rho=0.0, \mathrm{EI}=1.77 \times 10^{6} \mathrm{~N} \cdot \mathrm{m}^{2}, \mathrm{GK}=0.380 \times 10^{6} \mathrm{~N} \cdot \mathrm{m}^{2}, \mathrm{~h}=0$, and a frame cross-section area of $1.66 \times 10^{-3} \mathrm{~m}^{2}$. These properties correspond to a rectangular cross section that is roughly $200 \mathrm{~mm}(2 \mathrm{H})$ by $75 \mathrm{~m}(2 \mathrm{~W})$, with a wall thickness of $3.2 \mathrm{~mm}$. Hence, for this particular frame, the $\rho=0$ condition is an artiface used in the analysis to study the offset sensitivities.*

The membrane used in the NASTRAN comparisons was assumed to be $0.254-\mathrm{mm}$ thick with a Young's modulus of $200 \times 10^{9} \mathrm{~Pa}$ and a Poisson's ratio of 0.3 . Figure 7-1 shows the maximum vertical displacement of the frame between the supports as a function of pressure. Over the range of pressures that are considered, the displacement is nearly linear with pressure and is dependent on the tension. The dependence on the tension results from the interaction of the membrane with the frame in two ways. The first response results as the membrane transmits the lateral pressure load to the frame thus satisfying vertical equilibrium.

The second interaction effect is that the membrane also induces a compressive stress in the frame, which enhances the vertical displacement of the frame. This is analogous to the effect experienced in a beam that is laterally loaded and compressed along its axis by opposing forces at both ends. It is seen that at higher tensions, the enhancement becomes greater, as would be expected. In fact at very high tensions, the enhancements due to the tension in the membrane grow quite dramatically in a nonlinear fashion as lateral pressure on the membrane is increased. Figure 7-1 shows that at low tensions, the lateral displacements approach the values predicted for rings loaded laterally only, with no membrane as predicted by McGuiness [9]. The corresponding frame deformations, as predicted by NASTRAN [2], are also shown in Figure 7-1. It is seen that the model and NASTRAN predictions agree quite closely, with the disagreement increasing with pressure. The simple model predictions are slightly less than those predicted by NASTRAN, and the maximum disagreement occurs at $90 \mathrm{~Pa}$ and is less than $5 \%$. For reference, $90 \mathrm{~Pa}$ corresponds to a normal dynamic wind pressure (normal to the reflective surface) that would be experienced in a $12-\mathrm{m} / \mathrm{s}$ (27-mph) wind.

*Frames with $\rho=0 \mathrm{can}$, however, be designed. 


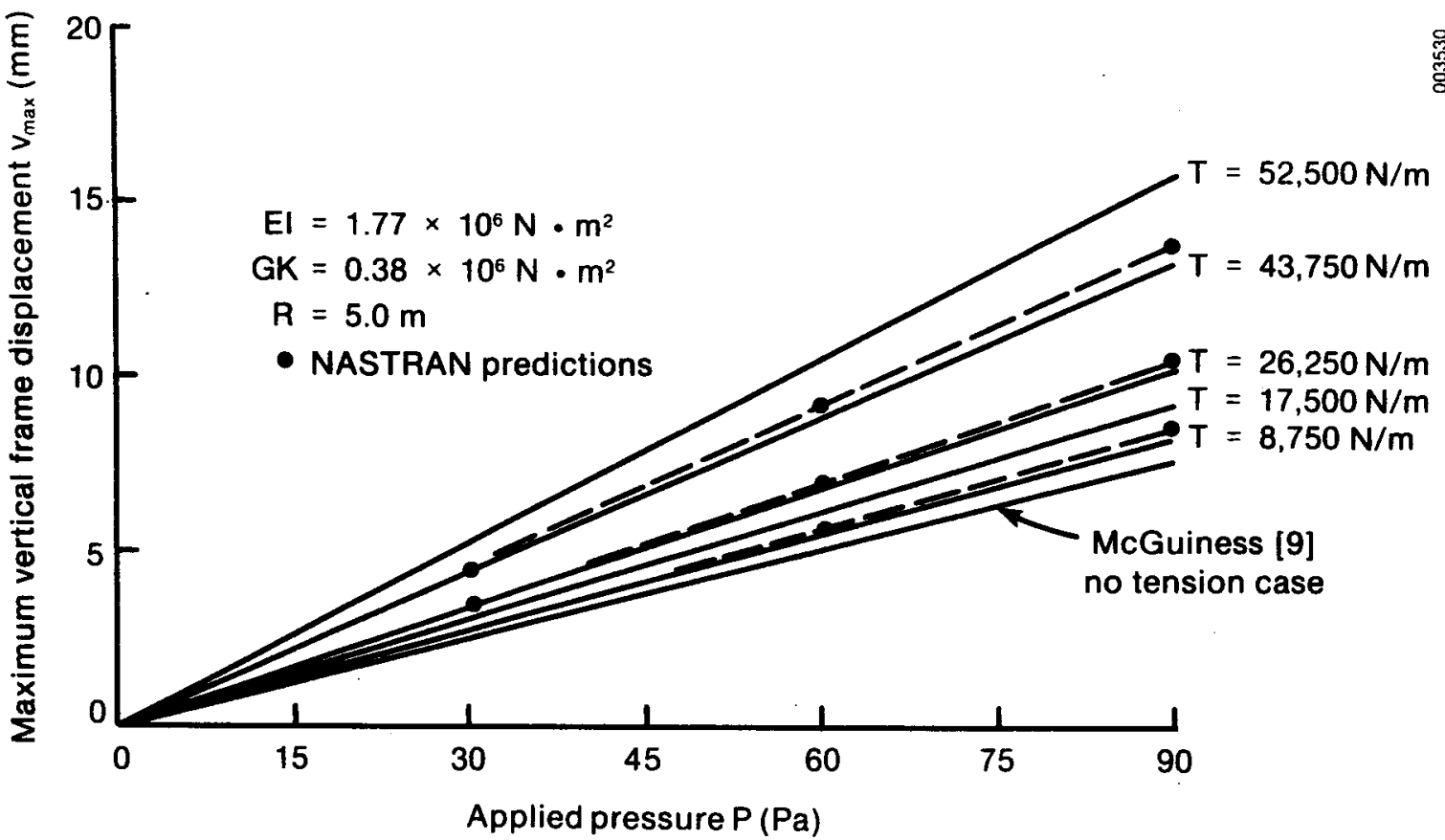

Figure 7-1. Maximum Vertical Displacement of the Ring Frame Midway between the Supports as a Function of Applied Lateral Pressure for Several Different Membrane Tensions. Also shown are the NASTRAN predictions and the predictions by McGuiness [9] for a line load (no lateral membrane tension) normal to the ring but equivalent to the corresponding lateral pressure load.

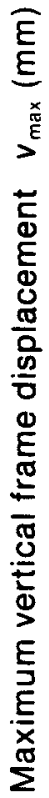

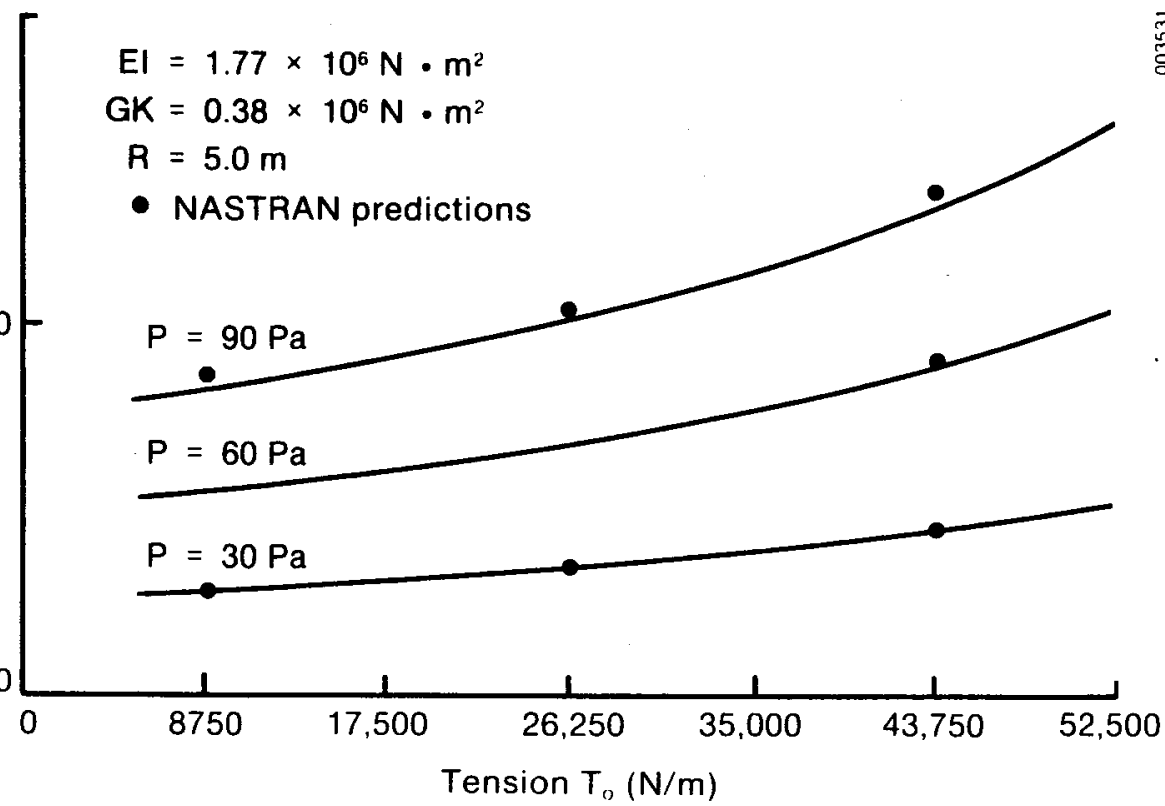

Figure 7-2. Maximum Vertical Displacement of the Ring Frame Midway between the Supports as a Function of Menbrane Tension for Several Applied Lateral Pressures 


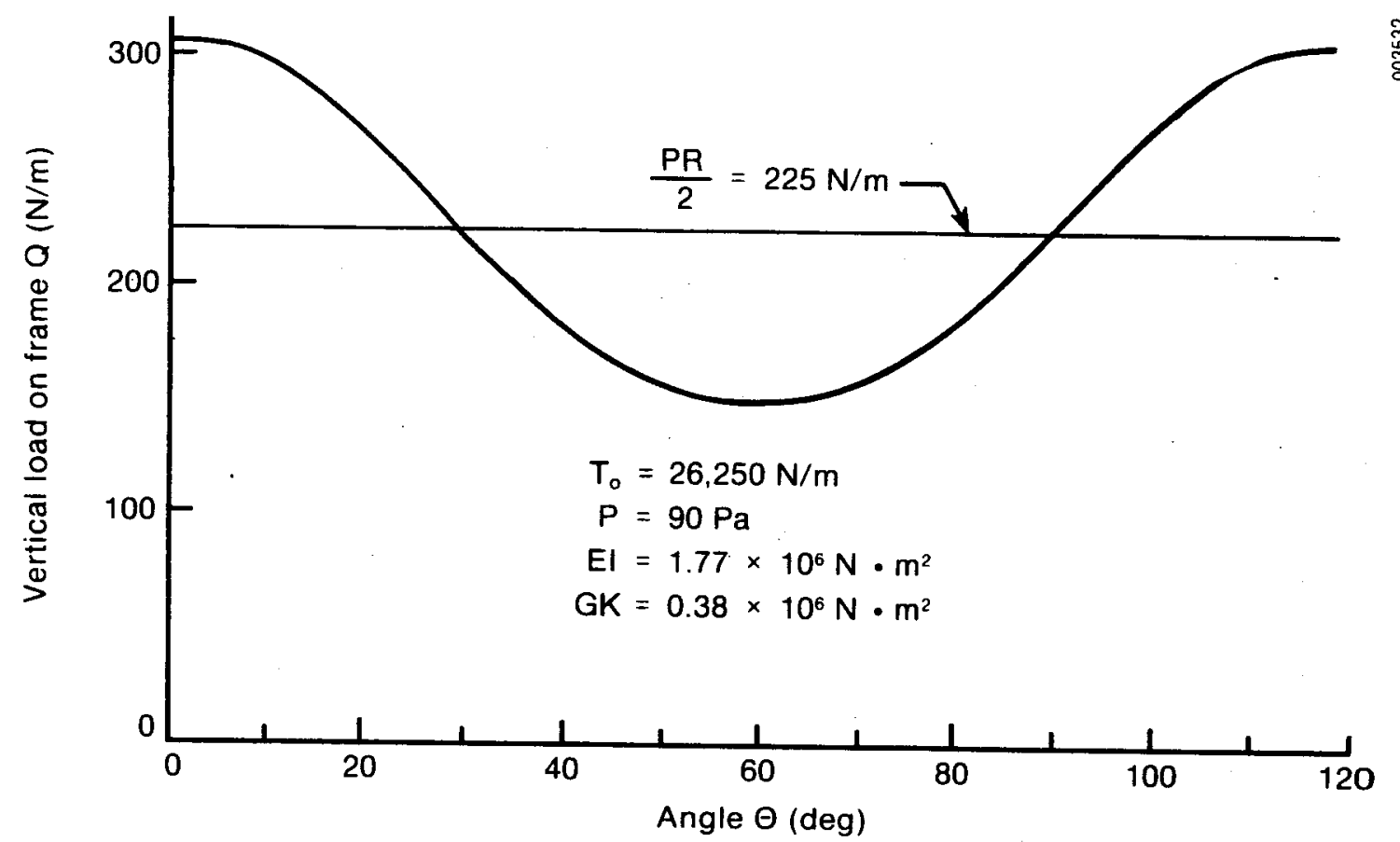

Figure 7-3. The Vertical Load Applied to the Frame by the Nembrane at the Attachment Point as a Function of Circunferential Angle $\theta$

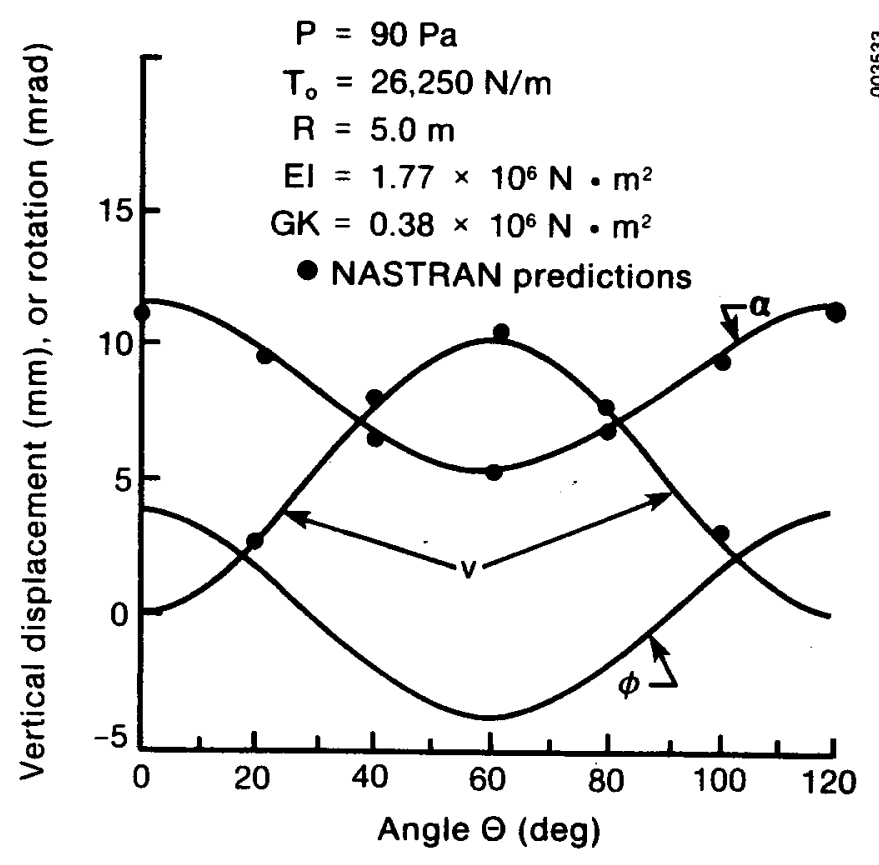

Figure 7-4. Vertical Displacement of the Frame, Frame Rotation, and Membrane Slope at the Attachment Point, $\Delta 11$ as a Punction of the Circumferential Coordinate $\theta$. All quantities are at the
attachment points. 


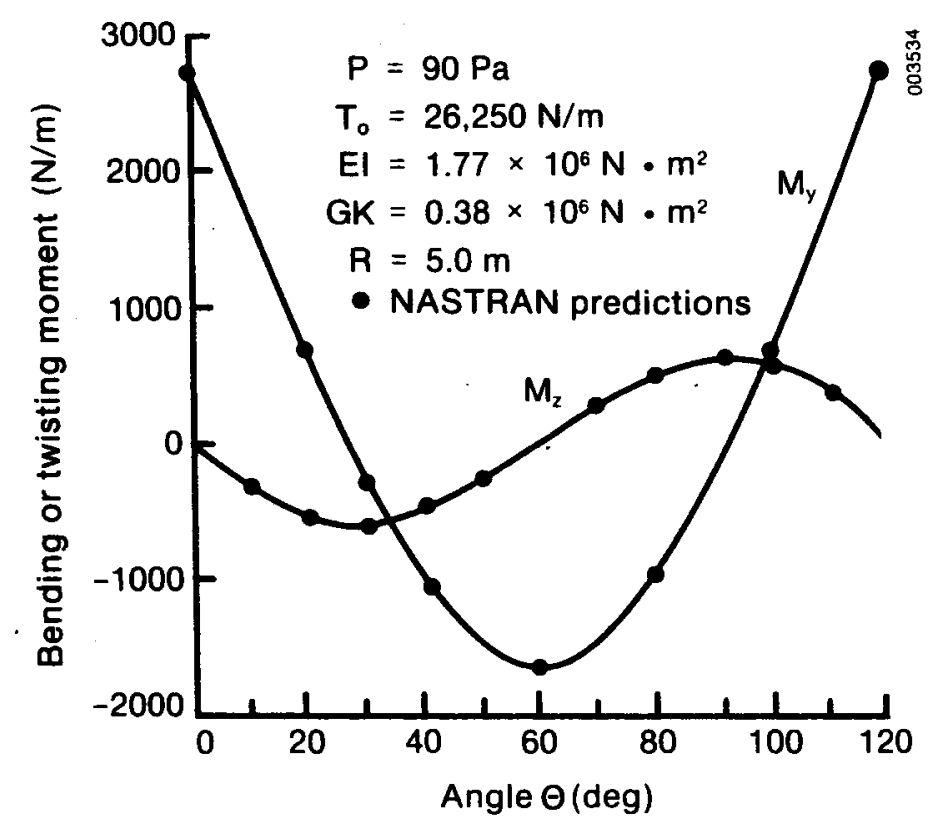

Figure 7-5. The Bending and Tristing Moment on the Frane Resulting from the Out-of-Pressure Loading on the Hembrane as a Function of Circumferential Coordinate $\theta$

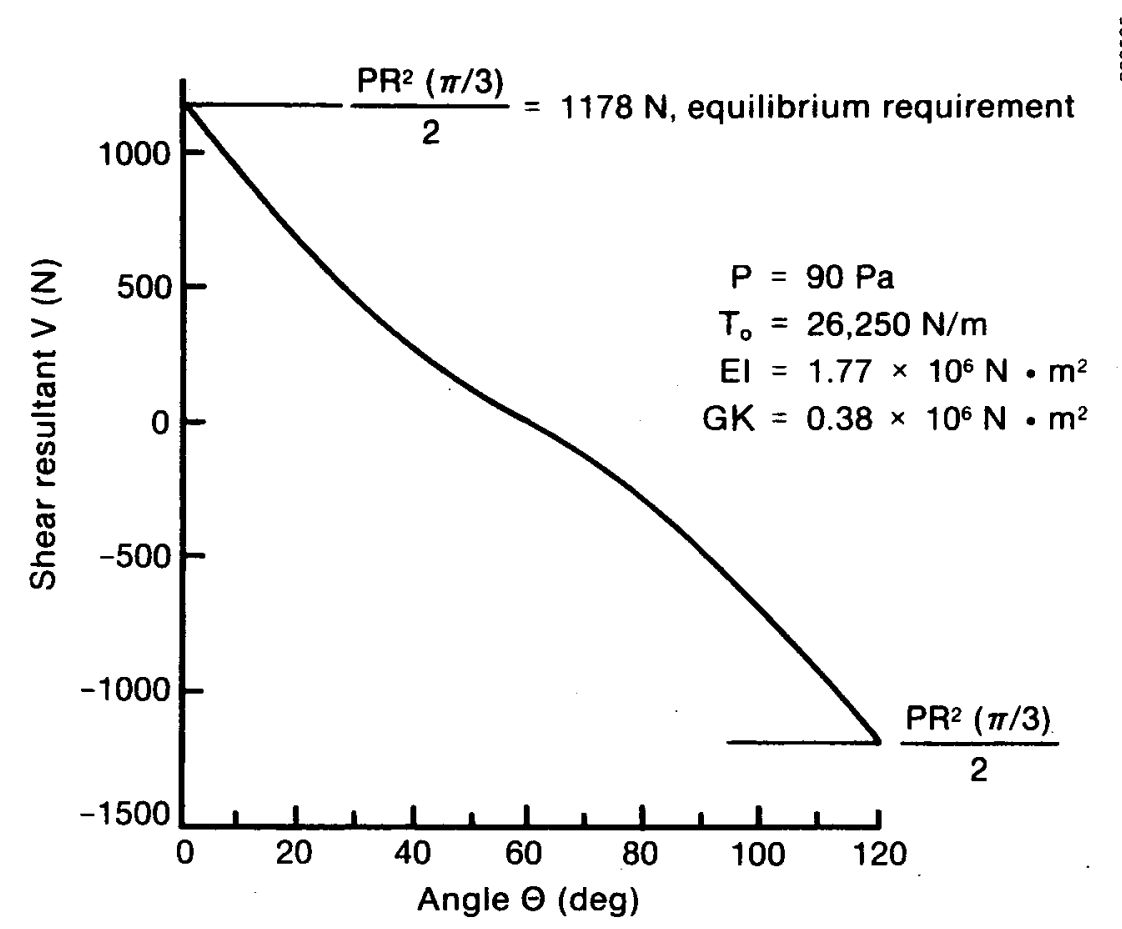

Figure 7-6. Vertical Frame Shear Resultant as a Function of Circunferential Coordinate $\theta$ 
Figure 7-2 shows the maximum vertical displacement of the frame member as a function of tension for several pressure levels applied to the membrane. Even at fairly low constant pressures, there is a definite nonlinear dependence on the membrane tension. The nonlinearity is more pronounced at the higher tensions and is due primarily to the load-displacement interaction in the compressed frame as previously discussed. The increasing nonlinearity with tension is also consistent with the trends anticipated from stability considerations. Also, Figure 7-2 shows the NASTRAN predictions, which show quite close agreement (as in Figure 7-1) over the range of parameters considered. Finally, the large displacements that can occur with very high tensions are not of major concern for practical and well-designed stable systems since, in these cases, the frame would be designed so that the nonlinear displacement regimes and stability limits would be well beyond the normal operating tensions required for optically accurate frame-membrane combinations.

Figure 7-3 illustrates the variation of the vertically applied load $Q(\theta)$ caused by the membrane around the frame. As the membrane deforms, a vertical and a horizontal load resultant occur on the frame. As expected, the average of the vertical load on the frame should equilibrate the lateral applied pressure on the membrane, as seen in Figure 7-3 where the horizontal line corresponds to the average vertical load. It is interesting to note that the vertical load is highest at the supports and lowest midway between the supports because the membrane-frame combination tends to deform between the supports. The normal load is relieved in that region, resulting in a minimum energy configuration for the system. At the supports, since there is no freedom of vertical displacement, the structure cannot adjust to help reduce the load.

Figure 7-4 illustrates several displacement and rotational effects, all as a function of distance between the two supports along the frame for a tension of $26,250 \mathrm{~N}$ and a pressure of $90 \mathrm{~Pa}$. The top curve marked $\alpha$ shows the slope of the membrane relative to the horizontal, at the attachment as a function of $\theta$ between the supports. The slope of the membrane with respect to the horizontal is greatest at the supports and smallest at the center between the supports. The second curve illustrates the displacement distribution $v(\theta)$ of the beam vertically between the two supports. The variation indicates a maximum displacement at the center and zero vertical displacement and slope at the supports, which is consistent with the boundary conditions. The final curve shows the rotation of the frame $\phi(\theta)$ as a function of distance between the two supports. The frame actually rotates in a positive direction at both supports (i.e., rolls outward), being unconstrained in that coordinate direction (this is caused by the twist-bending interaction), and rotates to a minimum negative value in the center between the supports with zero rotation points midway between. Figure 7-4 also shows the corresponding NASTRAN predictions for the various quantities; again quite close agreement is apparent.

The shape of the vertical displacement curve can be inferred from the boundary conditions, along with applied loading as shown in Figure 7-3. The shape of the membrane attachment angle can be inferred by considering the symmetry conditions and the vertical displacement. The symmetry conditions imply zero variation of $\alpha$ with $\theta$ at and midway between the supports. The maximum vertical displacement of the frame in the center between the supports will result in a minimum $\alpha$ at that point. The shape of the $\phi$ curve can be inferred from 
the boundary conditions (zero slope at the supports) and the displacement compatibility conditions. As the frame displaces upward, it will tend to rotate in a negative direction, with a minimum (i.e., maximum negative) rotation occurring at the midpoint between the supports.

Figure 7-5 illustrates the predicted bending moments in the frame as a function of the $\theta$ position along the frame. The bending moment about the $y$ axis, which is due primarily to the applied vertical load and the induced vertical shear, is analogous to the bending moment induced in a straight beam compressed at both ends and loaded laterally with a variable vertical load, such as presented in Figure 7-3. The twisting moment, which is quite moderate compared to the bending moment, is induced by the interaction of bending and rotation of the frame, which in turn is caused by the membrane. This effect occurs primarily as a result of the moment curvature relation, as described by Eq. 3-6. Considerations of the displacement variations in $v$ and $\phi$, as presented in Eq. 3-7, can predict the illustrated effects. Also the shape of the twist moment curve can be inferred from symmetry arguments (i.e., twist moments must be zero at and midway between the ends). In general, there will be an additional small effect caused by the membrane attachment horizontal offset ( $p$ ) from the center of rotation and the deformation of the membrane. More about this will be mentioned later. As before, the NASTRAN predictions corresponding to the simple-solution predictions show quite good agreement.

Figure 7-6 illustrates the effect of vertical internal frame shear as a function of distance between two supports. The shear at the ends satisfies the overall equilibrium conditions; also the shear curve is nonlinear, which is caused by the variation of the applied vertical shear load described in Figure 7-3 (see also Eq. A-6 in Appendix A).

Figures 7-7 and 7-8 demonstrate the deformation pattern predicted for the membrane and also demonstrate the agreement of the simplified solution with the NASTRAN predictions. Figure $7-7$ is a plot of the membrane deflection $w$, as a function of the circumferential coordinate. The figure presents predictions for several values of the radius $r$. Near the rim (i.e., at $r=R=5.0 \mathrm{~m}$ ) the deformation process follows that of the frame very closely, which is required by compatibility, and as the radius becomes smaller, the variation becomes attenuated. As the radius approaches zero, there is little $\theta$ dependence. The radial decay of the nonsymmetric deformation contribution, as shown in the figure, can be inferred from Eq. 4-7 (i.e., for $w_{2}$ ). It is noteworthy that although the solution for the simple model is linear, there is extremely good agreement with the NASTRAN solution, and the agreement becomes better as the radius becomes smaller. Even at large radii, only a $2 \%-3 \%$ difference is apparent.

Figure 7-8 shows the dependence of the membrane deformation on the radial coordinate directly for two values of $\theta$. The NASTRAN predictions for the total membrane deformation are quite close to the simple solution results that would be expected from the previous good agreement. Additional curves shown in Figure 7-8 also illustrate how the two components corresponding to the axisymmetric sag (i.e., $w_{1}$ in Eq. 4-6) of the membrane and to the nonsymmetric portion are induced by the frame deformation (i.e., $w_{2}$ in Eq. 4-7). 


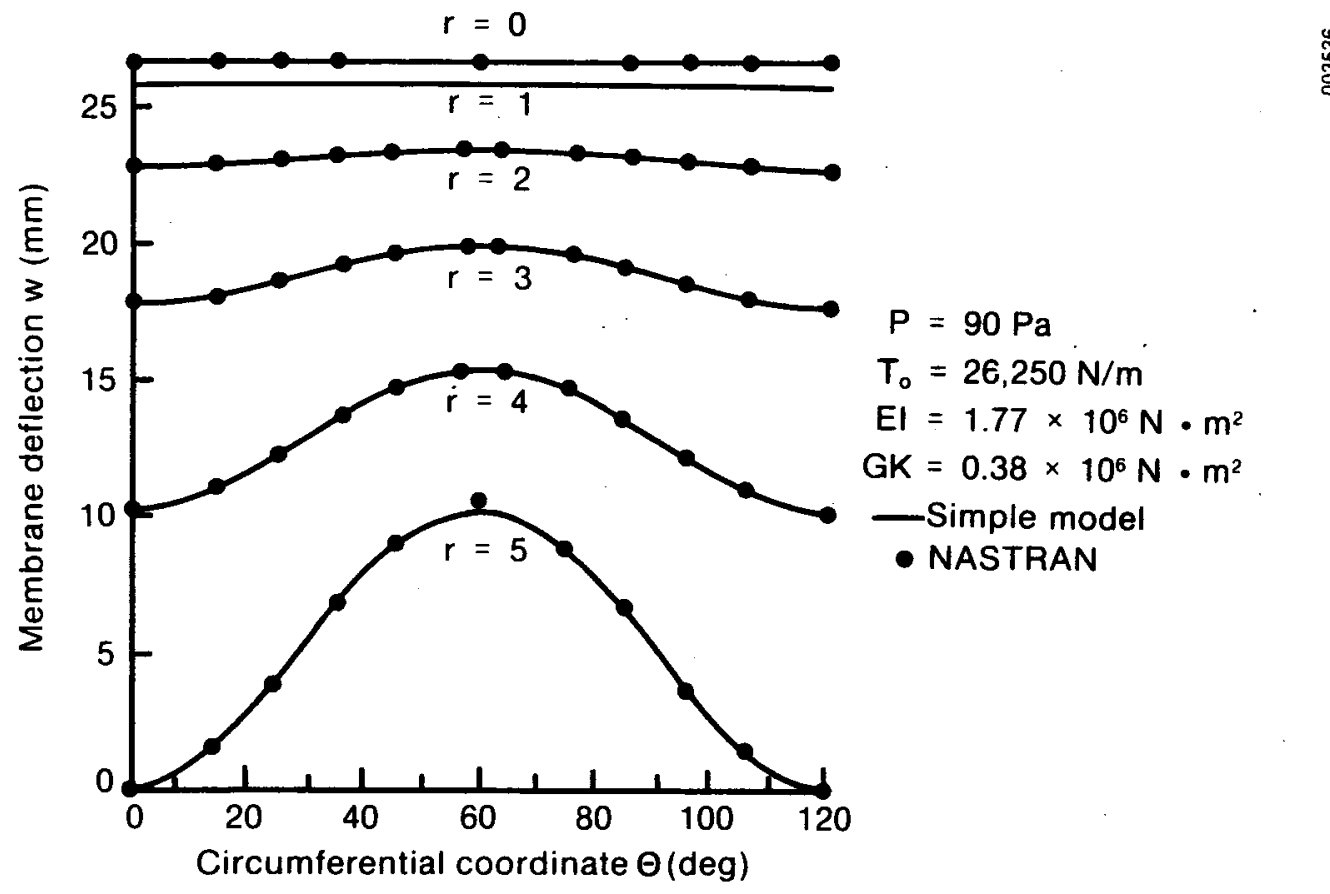

Figure 7-7. Normal Nembrane Deformation $w$ as a Function of the Circunferential Coordinate $\theta$ for Several Values of the Radius. Note that the curve for $r=5.0 \mathrm{~m}$ corresponds to the attachment point of the membrane to the frame.

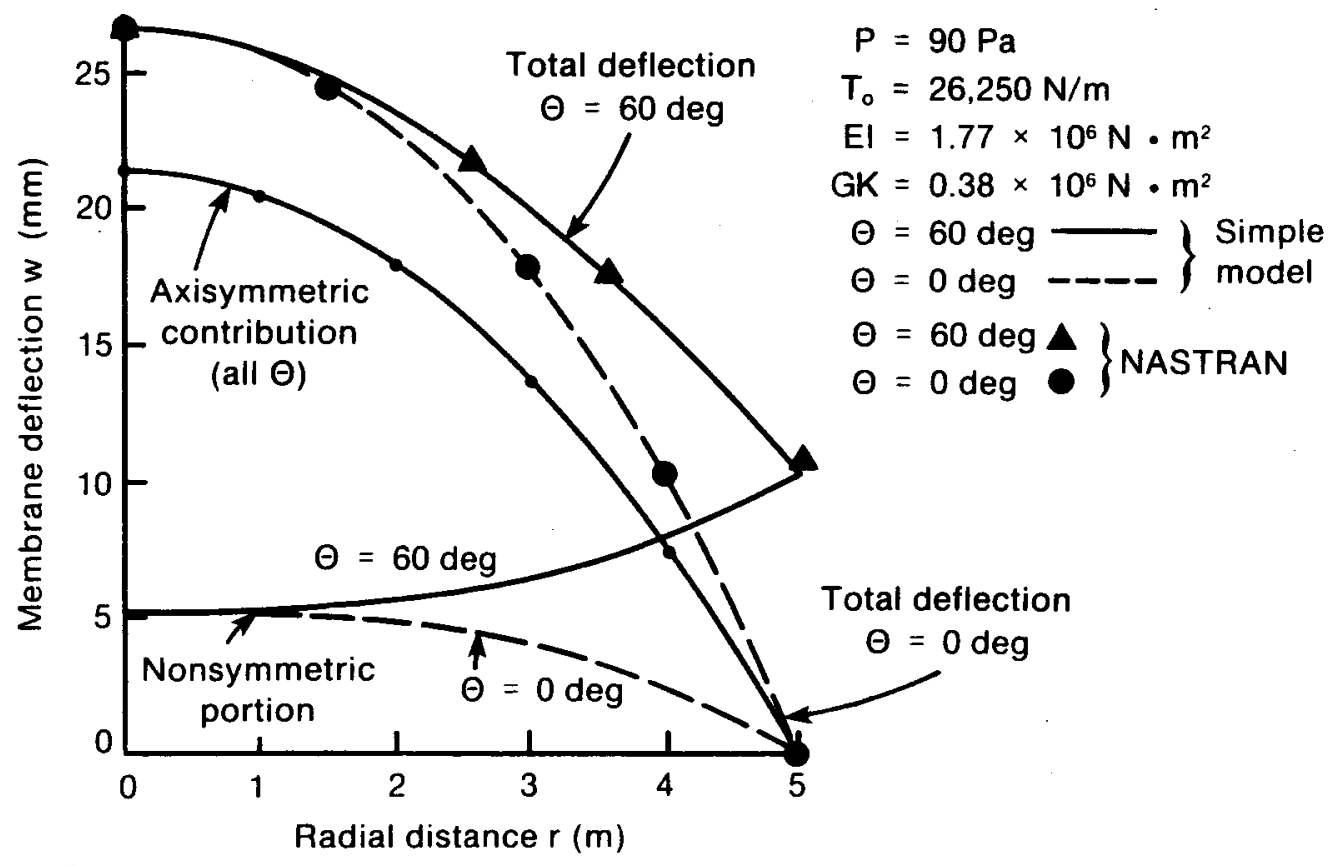

Figure 7-8. Normal Membrane Defornation $w$ as a Function of Radial Distance from the Membrane Center for Two Values of $\theta$. Also presented in this figure are the relative contributions for the axisymmetric and nonsymmetric deformation elements as a function of radius for the two values of $\theta=60^{\circ}$ and $\theta=0^{\circ}$. In addition NASTRAN predictions are presented by the symbols noted above. 
Physically, the symmetric portion $w_{1}$ corresponds to the deflection of the membrane due to the wind and weight load, but with the edges fixed at zero deflection. Conversely, the nonsymmetric portion of the deflection $w_{2}$ corresponds to zero wind and weight load but with the membrane edge deflected to conform to the deflected frame. The breakout for these two components of deformation is shown for $\theta=0 \mathrm{deg}$ and for $\theta=60 \mathrm{deg}$. Therefore, the nonsymmetric deformation contribution results in a net average vertical displacement of the membrane caused by the frame deformation. This effect can be visualized by considering the deformation of the frame between the two supports in a harmonic pattern and then locating the centroid of the harmonic pattern. Since the pattern is nearly symmetric between the minimum and maximum displacements, the centroid will lie approximately halfway between the displacement extremes. In Figure 7-8 the nonsymmetric deformation curves for $\theta=0 \mathrm{deg}$ (minimum frame deformation) and $\theta=60 \mathrm{deg}$ (maximum frame deformations) are nearly mirror images about a plane, which is about $5.18 \mathrm{~mm}$ above the zero displacement plane. By taking the midpoint between the deformation extremes of the frame for comparison, a 5.08-mm average displacement is predicted.

Figures 7-9 and 7-10 illustrate the measures of predicted surface deformation error as described in Eq. 6-6. Here again, we depict the RMS error contributions from the two displacement contributions along with the total error, which is the root mean square sum of the two RMS error contributions. The error contributions $\beta_{1}$ and $\beta_{2}$ correspond to the axisymmetric and nonsymmetric deformations $w_{1}$ and $w_{2}$, respectively.

Figures 7-9 and 7-10 both assume that no attempt has been made to actively control the axisymmetric portion of the membrane deformation. Thus these curves correspond to a passive design where a prescribed initial curvature is assumed, and the incremental displacement field corresponding to the applied pressure increment results in $\beta_{1}$ and $\beta_{2}$. Figure 7-9 illustrates the ratio of $\beta_{2}$ over $\beta_{1}$ as a function of the tension in the membrane for the same frame system considered in the previous figures. This curve is also valid for all pressure levels (or very nearly so) since both displacement contributions are found to be nearly linear with pressure (see Figure 7-1). Figure 7-9 also shows that the ratio of $\beta_{2}$ over $\beta_{1}$ is very small at low tensions and increases to significant values only as the tension becomes considerably higher. Thus the axisymmetric contribution $\beta_{1}$ dominates the error process at low-tomoderate tensions for the frame and loading condition being considered here. Further, for stiffer frames $\beta_{1}$ will be dominant over even a larger tension range.

In Figure 7-10, the total RMS surface error $\beta_{T}$ (solid curves) and $\beta_{1}$ (dashed curves) is plotted as a function of tension for the same frame as mentioned above and for two different pressure levels. The pressure levels of $30 \mathrm{~Pa}$ and $60 \mathrm{~Pa}$ would correspond [1] to a wind velocity that impinges the surface normally at about $7 \mathrm{~m} / \mathrm{s}$ and $10 \mathrm{~m} / \mathrm{s}$, respectively. Here again, the dominance of $\beta_{1}$ as a contribution to $\beta_{\mathrm{T}}$ is illustrated. The total error measure, which corresponds to axisymmetric deformation $\beta_{1}$, can be approximated quite accurately until the tensions exceed about $35,000 \mathrm{~N} / \mathrm{m}$ (for the frame and loading under consideration). 


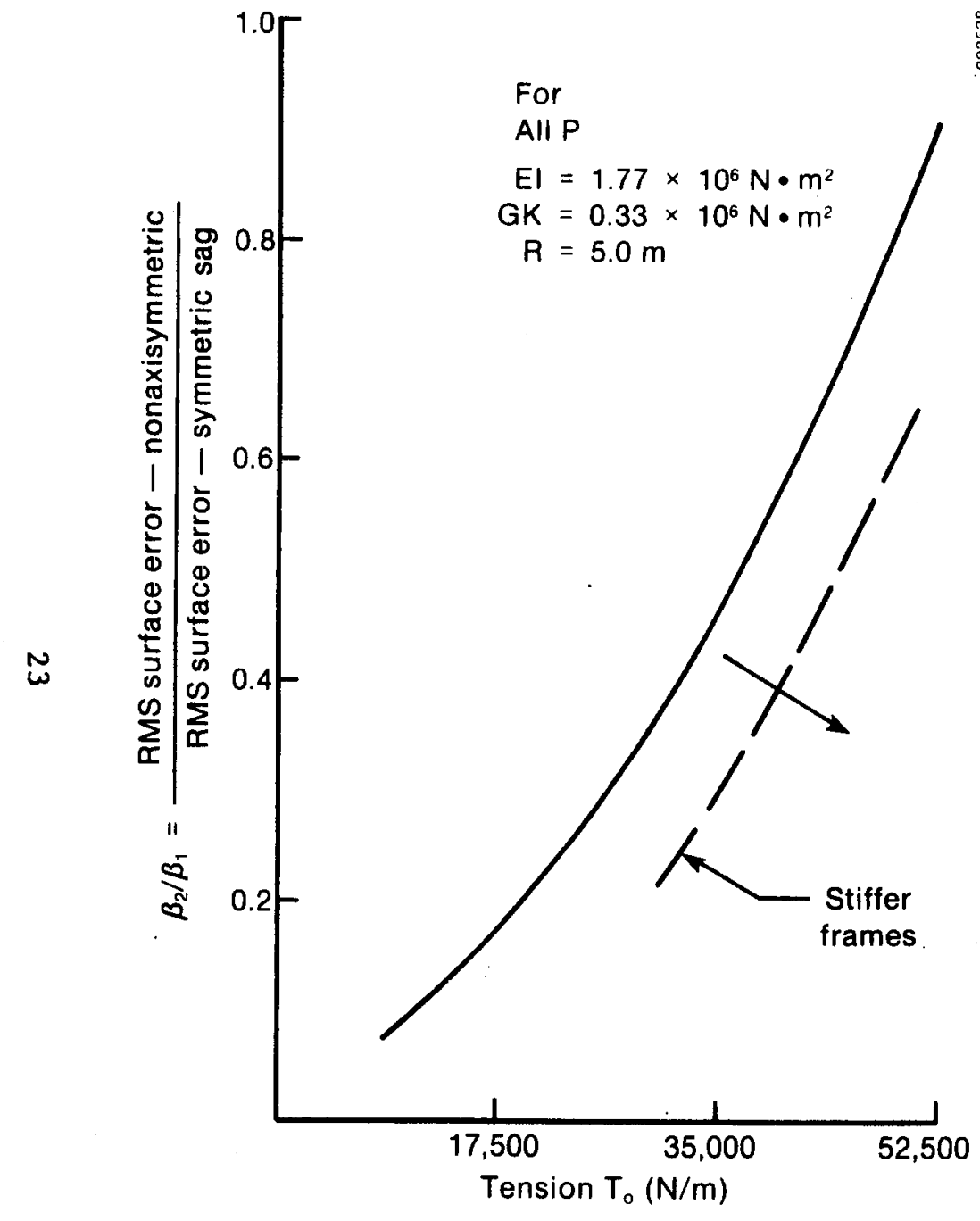

Figure 7-9. The Ratio of DMS Surface Errors $\left(\beta_{2} / \beta_{1}\right)$ as a Function of Tension in the Vembrane. $\beta_{2}$ and $\beta_{1}$ correspond to the RMS surface error contributions from the nonaxisymmetric deformation and axisymmetric deformation patterns, respectively.

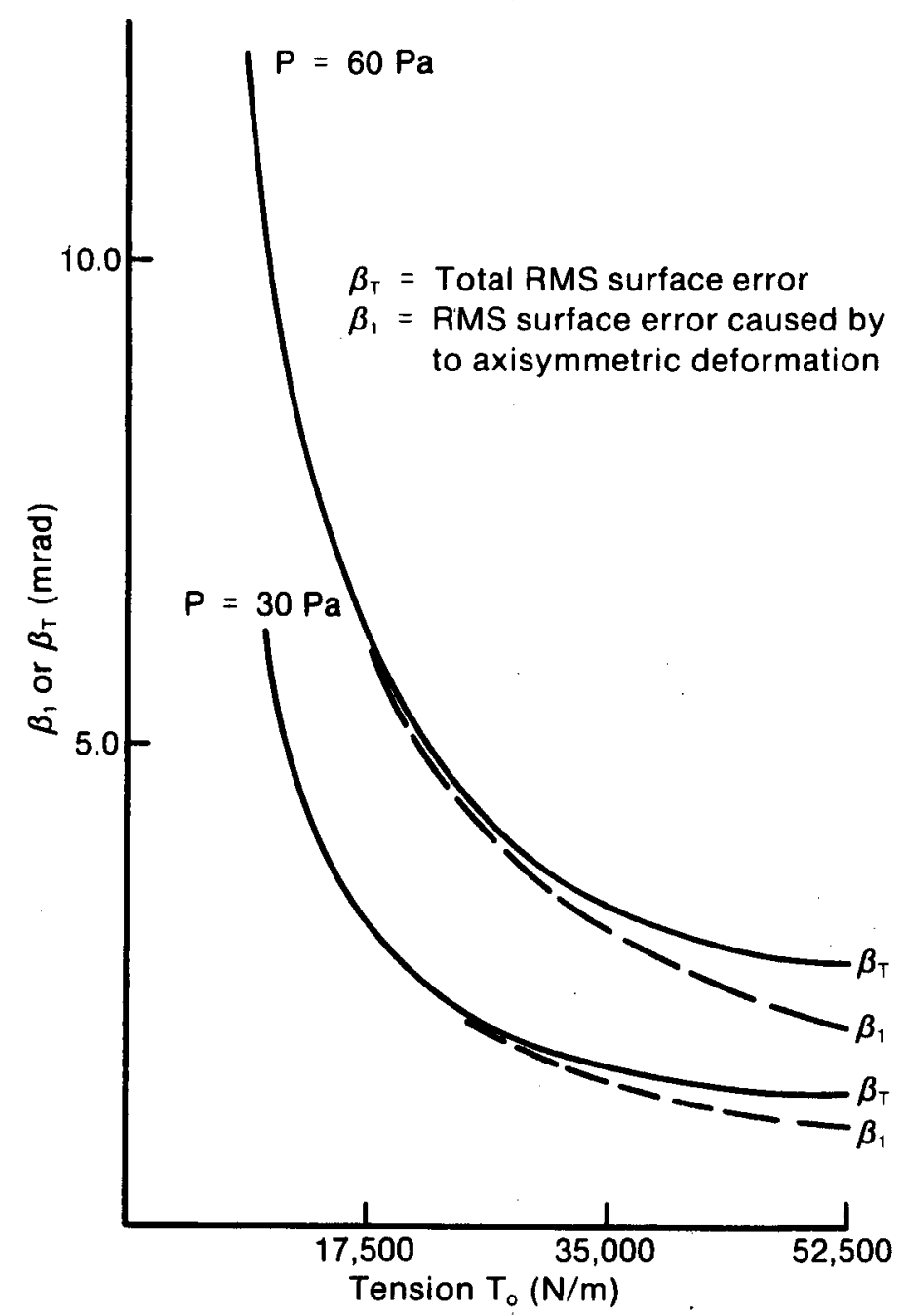

Figure 7-10. $\beta_{T}$ and $\beta_{1}$ as a Function of Helubrane Tension. $\beta_{1}$ and $\beta_{T}$ correspond to the RMS surface error contributions corresponding to the axisymmetric deformation portion and the total deformation of the membrane. 
It should be noted that changing the frame stiffness will not mitigate $\beta_{1}$ to any appreciable extent. However, $\beta_{2}$ can be easily decreased by increasing the stiffness of the frame to bending and twisting (EI and GK) stiffnesses. On the other hand, the only way the designer can decrease $\beta_{1}$ for the single stretched-membrane concept analyzed here is to increase the tension or to operate the stretched membrane at a lower operating pressure. If necessary, however, active control of the reflector membrane can be used to eliminate, or at least greatly reduce, the effect of $\beta_{1}$ at some increase in cost and complexity. It also should be noted that the pressures indicated on Figure 7-10 are probably higher than one would design for. Hence, the error associated with the axisymmetric portion could be considerably lower than this figure implies. However, since the analysis has been performed to illustrate structural response phenomena and the predictions of the model, this issue will not be discussed further at this point but will be relegated to a future report that will delve into these issues in more detail.

We will now discuss several other important effects that have been studied. First, the effect of the horizontal offset $\rho$ (see Figure 2-2) is quite moderate for the case studied in Figures 7-3 through 7-7. Little change in frame vertical displacement occurs when the value of $\rho$ changes if the pressure is also adjusted to keep the total load on the membrane constant. For example, if $\rho$ is changed from 0 to $0.0381 \mathrm{~m}$ (which is consistent with the frame cross section selected), the maximum vertical frame displacement for the two cases is identical to four significant figures. Increasing $\rho$ to $0.1,0.2$, and $0.3 \mathrm{~m}$ (while holding GK and EI constant), the maximum vertical displacement decreases from $10.15 \mathrm{~mm}$ (for $\rho=0$ ) to $10.14,10.12$, and $10.09 \mathrm{~mm}$, respectively. Vertical displacement decreases slightly because, due to the offset, the moment arm twists the frame in the opposite direction from which it would want to rotate for the $\rho=0$ case in the region where the vertical displacement is a maximum. Thus, comparing the peak rotations for the $\rho=0$ case to the $p=0.3$ case, it was found that the maximum positive rotation at the supports (minimum vertical displacement region) increases from 3.9 mrad to $4.8 \mathrm{mrad}$, but in the region of maximum vertical displacement the negative rotation is retarded from $-3.6 \mathrm{mrad}$ to $-2.7 \mathrm{mrad}$.

Though we have not studied the vertical offset problem in detail, the analysis already done indicates a number of trends. The vertical offset effect $h$, as shown in Figure 2-2 and as predicted with the simple analysis, is minimal (see Appendix A, Eqs. $A-10$ and $A-11$ ) and has only a small nonlinear dependence. The simple model results agree with the NASTRAN results as long as the other model assumptions hold (primarily the assumption of constant membrane tension).

To illustrate this consider a vertical offset case studied with both the simple model and NASTRAN, where the frame is defined as corresponding to the cases studied in Figures 7-3 to 7-7. The offset $h$ equals $100 \mathrm{~mm}$; the initial uniform ring twist is $37.63 \mathrm{mrad}$ for the initial tension, which we assume is $26,250 \mathrm{~N} / \mathrm{m}$. For a pressure loading of $\mathrm{P}=90 \mathrm{~Pa}$, the simple linear model predicts a maximum vertical displacement between the supports of $10.15 \mathrm{~mm}$ and a maximum rotation of $3.99 \mathrm{mrad}$, for both the offset and zero vertical offset cases. For the zero offset case, the NASTRAN method predicts a maximum vertical frame displacement of $10.45 \mathrm{~mm}$ and a frame rotation of $4.1 \mathrm{mrad}$. If the membrane is attached to the frame so that only radial loading is experienced 
at the attachment, the NASTRAN model predicts a maximum vertical frame displacement of $10.44 \mathrm{~mm}$ and a maximum rotation of $4.27 \mathrm{mrad}$ due to lateral loading. If on the other hand the membrane is assumed to be rigidly attached to the frame circumferentially as well as radially (i.e., as in welding or bonding), then the NASTRAN model predicts a maximum vertical frame displacement of $8.89 \mathrm{~mm}$ and a maximum rotation of $3.97 \mathrm{mrad}$. Thus, the difference in the boundary condition (i.e., attachment procedure) causes a noticeable decrease in the maximum vertical frame displacement.

For a radial constraint only, the simple model results agree quite closely with the NASTRAN predictions, where the membrane tensions were found to be constant over the membrane surface to within $1.0 \%$. For the rigid attachment case, the effect of the offset becomes quite noticeable because the bending of the frame causes additional compressive or tensile circumferential strain increments in the membrane near the attachment. Due to bending in the frame, the circumferential strain increment in the membrane must be equal to the frame strain increment at the attachment point. In essence, the membrane increases the effective bending resistance of the frame by the offset. For this case, tension nonuniformities of $\pm 16 \%$ were observed near the frame.

It is interesting to note that, for the case studied, the rotation (in the $z$ direction) of the frame did not seem to affect the membrane tension very much as we had anticipated. It might also be noted that for very thin membranes or for low-modulus membranes, the effect of the vertical offset should be mitigated even if the membrane were rigidly attached to the frame. Such considerations will be important if high-strength polymer structural membranes are used.

Similar results were obtained when the vertical offset problem was investigated with NASTRAN for the same frame as discussed above but for different loading and support conditions. The above effects are accentuated in this case, where a tension of $22,750 \mathrm{~N} / \mathrm{m}$ and zero pressure were used along with four vertical concentrated loads of alternating sign placed at 90 deg intervals around the frame. [The primary purpose of this configuration was to study potential stability problems corresponding to the lowest fundamental $(n=2)$ mode shape.] For the zero offset and the 100-mm offset (with radialonly constraint) cases, the maximum vertical frame displacement was predicted to be $44.8 \mathrm{~mm}$ and $44.7 \mathrm{~mm}$, respectively. The corresponding frame rotations were $11.56 \mathrm{mrad}$ and $11.43 \mathrm{mrad}$, respectively. When the membrane was rigidly attached, for the $100-\mathrm{mm}$ offset case, the maximum vertical frame displacement was predicted to be only $30.0 \mathrm{~mm}$ and the peak rotation was $8.28 \mathrm{mrad}$.

One response of interest that has emerged from evaluating and comparing the NASTRAN results with the results of the simple model is that in all cases where agreement is good, the membrane tension remains fairly constant though the radial displacement of the frame is not predicted to necessarily remain uniform around the circumference in the NASTRAN results. Thus, the frame tends to deform in such a way that the constant tension in the membrane is accommodated, as long as additional local strains in the membrane are not induced due to frame bending (i.e., as with the offset effect discussed above). It should be noted that the particular frame investigated for most of the comparisons in this report is fairly compliant in the radial direction, as compared with the membrane itself. It is anticipated that if the frame is 
stiffened significantly in the radial direction, more noticeable tension variations might be experienced; these would probably lead to some higher discrepancies in the relative predicted deformations by the simple method and the more detailed NASTRAN approach. Hence, since radial stability does not appear (from preliminary considerations) to be an issue, low radial stiffness presents no particular problems and is actually desirable from a design perspective since this should help to smooth out tension variations in the membrane.

The impact that torsional rigidity has on vertical displacement was also studied. For the single-membrane case the impact was significant, which can be seen intuitively from the strong twist/displacement coupling in Eqs. 3-3 through 3-6 and is demonstrated in Figure 7-11. The baseline case noted in Figure 7-11 corresponds to the case that was selected in Figures 7-3 through 7-7. As is shown in Figure 7-11, for the baseline case a 50\% decrease in torsional rigidity will increase the vertical frame deflection by about $50 \%$; but a $100 \%$ increase in torsional rigidity will decrease the frame displacement by about $20 \%$, and an infinite frame torsional rigidity will decrease the vertical displacement by about $40 \%$ relative to the baseline case. The trend is identical in form to that which would be anticipated [9] for laterally loaded but untensioned rings.

Though stability will not be addressed in detail here since the simple model cannot adequately elucidate many of the important stability issues, several

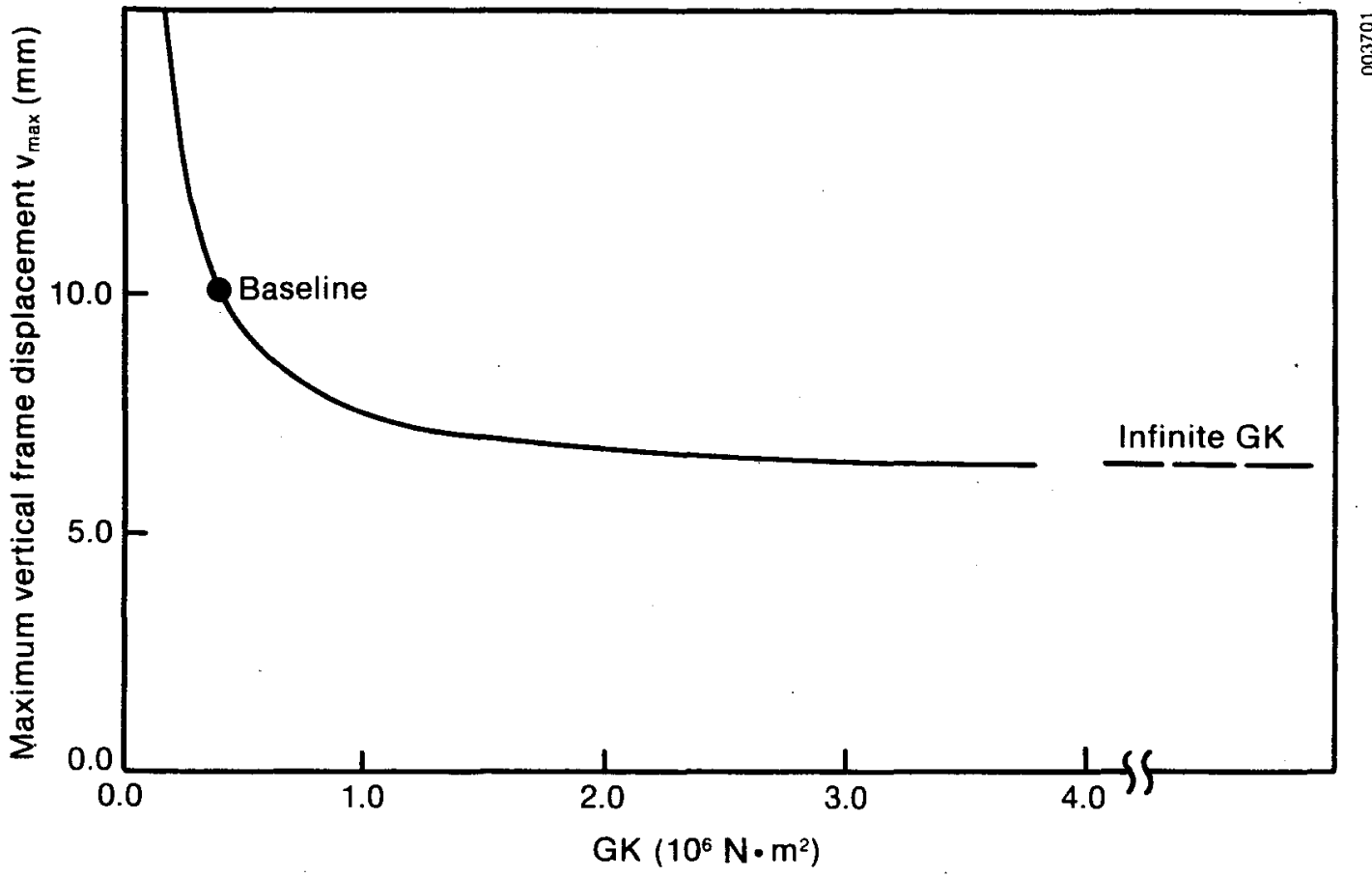

Figure 7-11. Effect of Torsional Rigidity on Vertical Displacement Frame 
design features and response mechanisms identified above can affect the stability of the frame-membrane assembly. The most obvious response related to a potential stability problem is the amplification of out-of-plane frame deformations by increased membrane tension. Although catastrophic collapse of the membrane-frame (based on analysis to be presented in a later report) does not appear to be a major problem, the tendency to amplify either initial imperfections (due to manufacturing tolerances) or other laterally load-induced, outof plane deformations at least to the point of unacceptable optical surface quality is present at some tension level. Further, the tendency exists for the membrane to mitigate or amplify lateral deformations in some situations. For instance, if no lateral loading of the membrane is present and the frame is initially warped out of plane, the membrane will introduce a shear load in the frame that will tend to decrease the vertical frame deformation, but a counteracting twist effect that will tend to increase out-of-plane deformations will also be present.

Other issues that have an impact on stability include dual membranes and offset effect, which becomes more important as deformations grow. The vertical offset effect not only becomes more pronounced at large deformations but the initial frame twist, induced by applying the membrane to the frame, also induces a bending stress in the frame. The bending stress can potentially affect gross buckling distortion and particularly local wall stability of thin-walled frames as well. To get a feel for the magnitude of the prestress caused by a vertical offset, consider the same case as presented in Figures 7-3 through 7-7. A membrane attached to the center of the frame under investigation would induce a nearly uniform compressive stress of about $78 \mathrm{MPa}$ $(10.7 \mathrm{ksi})$; however, if a single membrane were attached at a height of $100 \mathrm{~mm}$ ( $h$ in Figure 2-2) above the frame centerline, then an additional bending stress of $143 \mathrm{MPa}(20.7 \mathrm{ksi})$ would be present. Thus, for this case the peak local stress could be magnified three times (over the average compress Ive stress) by the offset. Finally, it might also be noted that the vertical offset effect, unless counteracted by a second rear-surface membrane, can cause further amplification of initial vertical frame distortions by virtue of the initial twist. 


\section{SECTIOI 8.0}

\section{CONCLUSIONS}

This report has identified a number of important structural response and design considerations that have an impact on the deformation performance and optical accuracy of stretched-membrane reflectors. The design considerations that were identified have been based on the analyses of single-membrane modules. However, based on comparative analyses of the single-membrane concept with a vertical of fset, we feel that many of the design considerations w11l also be directly related to double-membrane concepts. The model also provides a useful method for assessing the coupled membrane/frame problem and for evaluating structural design approaches and system trade-off studies requiring optical accuracy measures.

The mode1 and analyses presented here demonstrate the need to consider the coupled problem rather than the independent assessment of the ring and/or frame, which becomes especially important as the membrane tension increases. From the results presented above, we see that increased tensions accentuate the out-of-plane frame deformations due to the induced compressive load on the frame. This effect is important not only when considering the lateral pressure load and a frame with periodic supports but also when initial frame imperfections are considered because, as can be seen by analogy, the increasing tension in the membrane will tend to amplify initial imperfections in the frame and thus adversely impact the optical accuracy of the assembly.

Ignoring for the moment the direct coupling between the frame and the membrane and considering the membrane to be shaped to the contour of the frame, the twist/lateral deformation coupling of the frame is an important design consideration because nonuniform frame twist can, without the presence of lateral loading, induce out-of-plane frame and surface deformations. Further, a careful trade-off between torsional stiffness and bending stiffness of the frame is needed to minimize lateral deformations and the associated optical errors.

Another signficant consideration is the position and method of attaching the membrane to the frame. If the membrane is attached to the frame so that its plane does not pass through the frame shear center, an initial twist of the frame will be present prior to lateral pressure loading. This initial twist can amplify initial out-of-plane deformations and can induce a peak bending stress, which is up to three times as great as the average compressive stress, in the frame. Further, if the membrane is rigidly attached to the frame it can increase the effective bending stiffness of the frame and reduce the outof-plane frame and optical distortions.

The model developed in this report provides an accurate and simple method for predicting the structural response of single-membrane reflective modules in which the membrane passes through the frame shear center or in which the membrane is offset but attached so that only radial constraint is experienced. The model should also apply to cases in which the membrane is both offset vertically and rigidly attached if the membrane material is considerably more compliant than the frame material (i.e., as with polymer membranes and steel frames). Moreover, the model provides a convenient tool for evaluating and 
screening various designs and for system trade-off studies. Further, the model provides a conservative estimate for deflections (i.e., it overpredicts) when there is an offset membrane that is rigidly attached to the frame. Finally, the model can be modified, as outlined in Appendix $A$, to consider certain dual-membrane designs.

Some cautions with respect to the simple model are noteworthy. The model is not intended to be used for large deformation situations, stability analyses, or for any situation where the assumptions are violated to any significant extent (though it may be worthwhile if used wisely in conjunction with other more sophisticated stability assessments). For example, the model will give no insight into the effect of varying tension or membrane shear, which occurs when large frame distortions dominate. In a sense, the above cautions do not limit the use of the model since, as noted above, a well-designed reflective module will be both stable and sufficiently stiff for optlcal performance reasons and the resulting deformations will be small from a structural perspective.

Structural response and performance issues requiring the most immediate further investigation include: a detailed assessment of the stability of the frame-membrane combination under various loading conditions and constraint configurations, the assessment of structural and performance benefits of single- or double-membrane systems, allowable frame imperfections and their anticipated amplifications under different loading environments, the optimum number and type of frame supports, optical advantages of vacuum focusing versus laminate focusing, and nonuniform membrane surface loading effects. Further, experiments are needed to verify existing analyses and to identify where current procedures may be lacking. Finally, dynamic issues should be investigated to identify potential problems (such as low-frequency windinduced vibrations). 


\section{SECTION 9.0}

\section{REFERENCES}

1. Murphy, L. M., Technical and Cost Benefits of Lightweight, StretchedMembrane Heliostats, SERI/TR-253-1818, Golden, Co: Solar Energy Research Institute, May 1983.

2. Schaeffer, H. G., MSC/NASTRAN PRIMER--Static and Normal Mode Analysis: A Study of Computerized Technology, Mount Vernon, NH: Schaeffer Analysis, Inc., 1979.

3. Wu, Chien H., "Large Finite Strained Membrane Problems," Quarterly of Applied Mathematics, Vol. 36, Jan. 1979, pp. 347-359.

4. Wong, F. S., and R. T. Shield, "Large Plane Deformations of Thin Elastic Sheets of Neo Hookean Material," ZAMP, Vol. 20, 1969, pp. 176-199.

5. Yang, W. H., and W. W. Feng, "Axisymmetrical Deformations of Non-Linear Membranes," J. Appl. Mech., Vol. 37, 1970, pp. 1002-1011.

6. Fenner, W. J., and C. H. Wu, "Large Plane to Surface Deformations of Membranes with Inclusion," J. Appl. Mech., Vol. 87, June 1981, pp. 357-360.

7. Hogan, M. B., "Circular Beams Loaded Normal to the Plane of Curvature," J. App1. Mech., Vol. 5, 1983.

8. Tabakman, H. D., and H. P. Valentijn, "Distortion of Circular Rings," Mach. Des., 1964.

9. McGuiness, H., Solution of a Circular Ring Structural Problem, Tech. Rep. 32-178, Pasadena, CA: California Institute of Technology, 1961 .

10. Meck, H. R., "Three-Dimensional Deformation and Buckling of a Circular Ring of Arbitrary Section," J. Eng. Ind., 1969.

11. Blake, A., "Stress in Curved Beams," Mach. Des., 1974.

12. Levy, Roy, "Displacements of Circular Rings with Normal Loads," Proc. Am. Soc. Civil Eng., J. Struct. Div., Vol. 88, No. 1, Feb. 1962.

13. Blake, Alexander, "Deflection of a Thick Ring in Diametral Compression," J. Appl. Mech., Vol. 26, No. 2, June 1959.

14. Meck, H. R., "Three-Dimensional Deformation and Buckling of a Circular Ring of Arbitrary Section," J. Eng. Ind., Vo1. 91, No. 1, Feb. 1969.

15. Timoshenko, S. P., Theory of Elastic Stability, Second Edition, New York, NY: McGraw Hil1 Book Company, 1961, pp. 313-318. 
16. Oden, J. F., and E. A. Ripperger, Mechanics of Elastic Structures, 2nd Ed., New York, NY: McGraw Hill Book Company, 1981.

17. Mollmann, H., Introduction to the Theory of Thin Shells, New York, NY: John Wiley and Sons, 1981, pp. 160-161.

18. Mitche11, G. C., "Analysis and Stability of Floating Roofs," Proc. Am. Soc. Civil Eng. J. Eng. Mech. Div., Vol. 99, No. EM5, Oct. 1973, pp. 1037-1052.

19. Biggs, F., and C. N. Vittatoe, The Helios Model for the Optical Behavior of Reflecting Solar Concentrators, SAND 76-0347, Albuquerque, NM: Sandia National Laboratories, Mar. 1979. 


\section{APPENDIX A}

\section{FRAME EQUILIBRIUA BQUATIONS}

Consider an incremental frame element of length $R \Delta \theta$ as shown in Figure A-la and $b$ where the coordinate directions are as described in Figure 2-2 in the main body of the text. First consider the moment balance for twist about the point 0 in the figure; then in the $z$ direction

$$
\left(\mathrm{M}_{\mathrm{z}}+\Delta \mathrm{M}_{\mathrm{z}}\right) \cos \Delta \theta-\mathrm{M}_{\mathrm{z}}+\left(\mathrm{M}_{\mathrm{y}}+\Delta \mathrm{M}_{\mathrm{y}}\right) \sin \Delta \theta+\mathrm{M}_{\mathrm{o}} \mathrm{R} \Delta \theta=0
$$

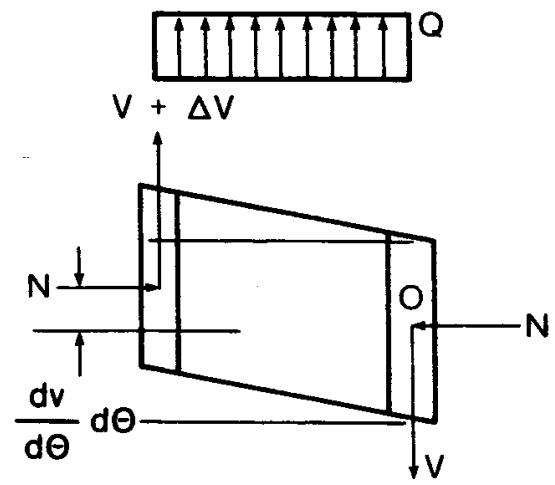

a) Radially outward view of frame element

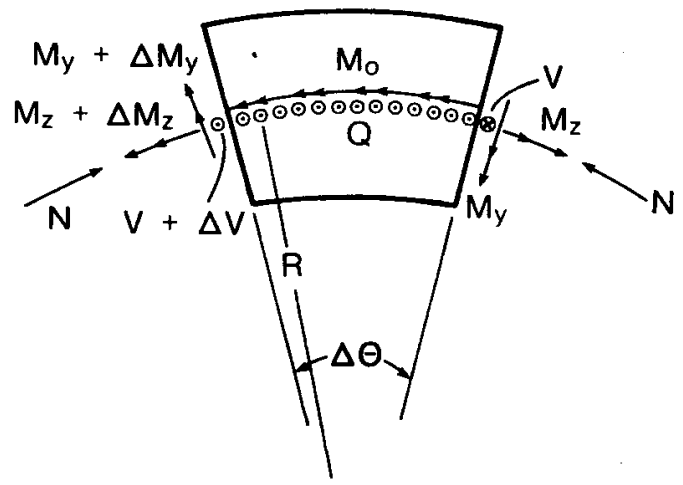

b) Top view of frame element

Figure A-1. Equilibrium Forces on an Incremental Element of the Frane 
where $M_{O}$ is the applied torque per unit length caused by the membrane and as measured along the circumference of the frame centroid (see Figure A-1b). Then let $\Delta \theta$ approach zero and Eq. A-1 now becomes

$$
\frac{\partial M_{z}}{\partial \theta}+M_{y}+M_{o} R=0 \text {. }
$$

Consider now moments in the $y$ direction (about point 0 ), then

$\left(M_{y}+\Delta M_{y}\right) \cos \Delta \theta-M_{y}-\left(M_{z}+\Delta M_{z}\right) \sin \Delta \theta+(v+\Delta v) R \Delta \theta+N \Delta v=0$,

where $V$ is the shear resultant as defined in Figure $A-1 . N$ is the hoop compressive force on the frame caused by the radially inward membrane induced load.

Again, letting $\Delta \theta$ approach zero results in the following equation:

$$
\frac{\partial M_{y}}{\partial \theta}-M_{z}+V R+N \frac{\partial v}{\partial \theta}=0 \text {. }
$$

It is interesting to note here that if Eq. A-4 is solved for $V$, contributions in addition to those from $M$ result. That is, coupling effects with the twist moment $M_{z}$, and with the ring compressive force $N$, appear.

The shear resultant can be determined from the vertical equilibrium, or

$$
\mathrm{V}+\Delta \mathrm{V}-\mathrm{V}+\mathrm{QR} \Delta \theta=0,
$$

where $Q$ is the vertical load per unit length caused by the membrane, which results in

$$
\frac{\partial V}{\partial \theta}+Q R=0,
$$

as $\Delta \theta$ approaches zero.

By using Eq. A-6, Eq. A-4 may now be written as

$$
\frac{\partial^{2} M_{y}}{\partial \theta^{2}}-\frac{\partial M_{z}}{\partial \theta}-Q R^{2}+N\left(\frac{\partial^{2} v}{\partial \theta^{2}}\right)=0 \text {. }
$$

It now only remains to determine $Q$ and $M_{0}$ as a function of the membrane tension $\mathrm{T}_{\mathrm{o}}$, the geometry, and the deformations. First consider radial equilibrium of the frame, which requires that

$$
\mathbf{N}=\mathbf{T}_{\mathrm{o}} \mathbf{a}
$$

Then from Figures $A-1 b$ and $A-2$ it is seen that for an element of length $R \Delta \theta$,

$$
\mathrm{QR} \Delta \theta=\mathrm{T}_{\mathrm{o}} \mathrm{a} \Delta \theta \alpha,
$$




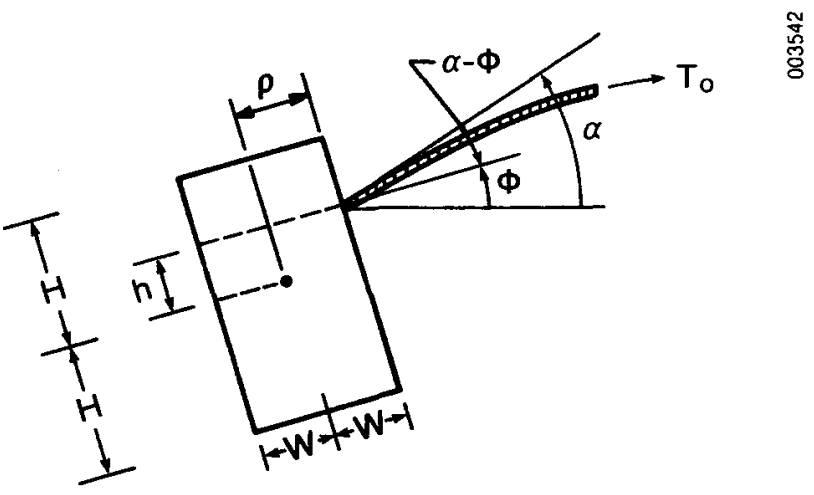

Circumferential view of frame-cross section

\section{Figure A-2. A Circumferential View of the Prane Cross Section and the Rotation Angle of the Prane as Well as the Relative Rotation of the Membrane to the Prane and the Horizontal}

or

$$
\mathrm{QR}=\mathrm{T}_{\mathrm{o}} \mathrm{a} \alpha \text {. }
$$

In determining the applied torque about the frame centroid $M_{0}$, the deformations of the membrane relative to the frame must be considered. Further by assuming linear superposition, only the moment increment contribution corresponding to the lateral loading is of interest, though there in general may be some initial applied moment about the frame due to a nonzero value of $h *$. This moment increment can be determined by taking the difference in the moments, induced by the membrane, before and after the lateral load is applied to the membrane. Taking such a difference results in the applied torque moment increment, due to the lateral load and deformation, about the frame centroid, which is given by

$$
M_{0} R=-T_{0}[(\rho \phi-\alpha \rho)+\alpha \phi h] a .
$$

\footnotetext{
*The initial deformation and stress state of an initially perfect ring is given in Appendix C.
} 
Then by taking only the first order terms, in $\alpha$ and $\phi$, the appropriate value for $M_{0} R$ is

$$
M_{0} R=T_{o^{a}} a(\alpha-\phi) p .
$$

It is seen from Eq. A-10 that even if an initial applied moment about the frame is present, due to a nonzero $h$ (of amount - $h T_{0} a / R$ ), it will impact the applied moment increment caused by lateral pressure loading of the membrane only in second order. Thus while the nonzero $h$ and the corresponding initial stress state will impact stability considerations, it will have a negligible effect on the small deformation problem associated with a stable configuration. It should be noted, however, that the discussion above is valid only if the assumption of constant tension remains valid. It is anticipated that significant inaccuracies may result as this assumption is violated.

The desired equilibrium equations can now be written by combining Eqs. A-9 and A-11 with Eqs. A-7 and A-2, respectively. The resulting equations are given by

or

$$
\frac{\partial M_{z}}{\partial \theta}+M_{y}+T_{o} a(\alpha-\phi) \rho=0,
$$

$$
\frac{\partial^{2} M_{y}}{\partial \theta^{2}}-\frac{\partial M_{z}}{\partial \theta}-T_{0} \operatorname{Ra}\left[\alpha-\left(\frac{1}{R} \frac{\partial^{2} v}{\partial \theta^{2}}\right)\right]=0 .
$$

The last issue to be raised is related to the effect of multiple membranes. Two membranes have been suggested for focusing purposes [1] where a vacuum would be introduced between the surfaces to induce curvature and hence focusing. By considering the load introduced by each membrane separately the appropriate equations analogous to Eqs. $A-9$ and $A-11$ are given by

$$
\mathrm{QR}=\mathrm{a} \sum_{i=1}^{2} \mathrm{~T}_{\mathrm{oi}} \alpha_{i},
$$

and

$$
M_{o} R=\operatorname{ap}\left(\sum_{i=1}^{2} T_{o i} \alpha_{i}-2 \phi\right),
$$

where the subscript $i(=1,2)$ corresponds to the first and second membrane, respectively.

Then the governing Eqs. $\mathrm{A}-12$ and $\mathrm{A}-13$ become

and

$$
\frac{\partial M_{z}}{\partial \theta}+M_{y}+a \rho\left(\sum_{i=1}^{2} T_{o i} \alpha_{i}-2 \phi\right)=0,
$$

$$
\frac{\partial^{2} M_{y}}{\partial \theta^{2}}-\frac{\partial M_{z}}{\partial \theta}-a R \sum_{i=1}^{2} T_{o i} \alpha_{i}+a\left(\sum_{i=1}^{2} T_{o i}\right) \frac{\partial 2 v}{\partial \theta^{2}}=0 \text {. }
$$




\section{APPERD IX B}

\section{NUTER ICAL SOLUTION APPROACH}

There are numerous suitable approaehes that ean be followed to attain the solution of Eqs. 3-5 and 3-6. Sinee a numerieal iterative approach was seleeted to resolve the $\alpha(\theta)$ eoupling with Eq. 4-10, a straightforward and effieient numerieal approaeh for the eoupled Eqs. 3-5 and 3-6 was also deemed satisfaetory. The approach taken for the model presented here was to reduce the order of the two eoupled Eqs. 3-5 and 3-6 to six first order 1inear differential equations. Then, the resulting set of equations ean be written in the form

$$
\frac{d \vec{Y}}{d \theta}=D \vec{Y}+\vec{S}(\theta)
$$

where

$$
\vec{Y}=\left[v, v^{\prime}, v^{\prime}, v^{\prime}+, \phi, \phi^{\prime}\right]^{T},
$$

and $D$ is a square matrix of order six. The elements $D_{1 j}$ of $D$ are defined by

$$
\begin{aligned}
& \mathrm{D}_{43}=\left[\frac{\mathrm{GK}}{\mathrm{EI}}-\frac{\mathrm{R}^{2} \mathrm{aT}_{\mathrm{o}}}{\mathrm{EI}}-\left(1+\frac{\mathrm{GK}}{\mathrm{EI}}\right)\left(1+\frac{\mathrm{EI}}{\mathrm{GK}}\right)\right] \\
& \mathrm{D}_{45}=\mathrm{R} 1\left(+\frac{\mathrm{GK}}{\mathrm{EI}}\right)\left(\frac{\mathrm{EI}}{\mathrm{GK}}+\frac{\rho \mathrm{PT}_{\mathrm{o}} \mathrm{R}}{\mathrm{GK}}\right) \\
& \mathrm{D}_{63}=-\frac{1}{\mathrm{R}}\left(1+\frac{\mathrm{EI}}{\mathrm{GK}}\right) \\
& \mathrm{D}_{65}=\left(\frac{\mathrm{EI}}{\mathrm{GK}}+\frac{\rho \mathrm{PT}_{\mathrm{o}} \mathrm{R}}{\mathrm{GK}}\right) \cdot \\
& \mathrm{D}_{12}=\mathrm{D}_{23}=\mathrm{D}_{34}=\mathrm{D}_{56}=1
\end{aligned}
$$

A11 other terms are zero. The veetor $\vec{s}$ is defined by

$$
\vec{s}=\left[0,0,0, s_{4}, 0, s_{6}\right]^{T} \text {, }
$$

where

$$
S_{4}=\frac{R^{3} a T_{0} \alpha}{E I}\left[1-\frac{\rho}{R} \frac{E I}{G K}\left(1-\frac{G K}{E I}\right)\right],
$$

and

$$
\mathrm{S}_{6}=-\frac{\operatorname{RpaT}_{\mathrm{o}} \alpha}{\mathrm{GK}} \text {. }
$$

The required boundary eonditions at $\theta=0$ and $2 \pi / 3$ for Eq. $B-1$ ean be deseribed by

$$
\vec{Y}_{0}=\vec{Y}(0)=\left[0,0, v^{\prime \prime}(0), v^{\prime \prime}(0), \phi(0), 0\right] \text {, }
$$


and

$$
\overrightarrow{\mathrm{Y}}_{\mathrm{e}}=\overrightarrow{\mathrm{Y}}\left(\frac{2 \pi}{3}\right)=\left[0,0, \mathrm{v}^{\prime}\left(\frac{2 \pi}{3}\right), \mathrm{v}^{\prime} \mathrm{\prime}^{\prime}\left(\frac{2 \pi}{3}\right), \phi\left(\frac{2 \pi}{3}\right), 0\right]
$$

Eq. B-l is now easily solved by any number of procedures. A fourth order Runge Kutta proeedure was used for the analysis presented in this report. The only remaining diffieulty relates to the initial eonditions that must be speeified eorreetly to arrive at the solution. Thus, the initial starting veetor $\overrightarrow{\mathrm{Y}}_{0}$ must be known.

The veetor $\vec{Y}_{0}$ eannot be eompletely speeified initially sinee $v^{\prime}(0), v^{\prime} '(0)$, and $\phi(0)$ are unknown; nor are they arbitrary sinee they must be seleeted to satisfy $\mathrm{Eq} . \mathrm{B}-7$ as well. It is noted that if the solution for $\overrightarrow{\mathrm{V}}$ is unique, only one ehoiee for $v^{\prime \prime}(0), v^{\prime \prime}(0)$, and $\phi(0)$ will result in the first, second, and sixth elements in Eq. B-7 equal to zero. The seleetion of $v^{\prime \prime}(0)$, $v^{\prime \prime \prime}(0)$, and $\phi(0)$ ean be made and improved iteratively by using Newton Raphson's approach in the following manner. Let $v^{\prime \prime}(0), v^{\prime \prime}(0)$, and $\phi(0)$ form the eomponents of an initializing veetor $\vec{z}_{o}$, sueh that

$$
z_{0}=\left[v^{\prime \prime}(0), v^{\prime \prime}(0), \phi(0)\right]^{T} \text {; }
$$

then define the "end error veetor" by

$$
\vec{z}_{e}=\left[v\left(\frac{2 \pi}{3}\right), v^{\prime}\left(\frac{2 \pi}{3}\right), \phi^{\prime}\left(\frac{2 \pi}{3}\right)\right]^{T} \text {. }
$$

Thus, if a solution to Eg. B-1 is found, then $\vec{Z}_{e}$ (the error vector) will be identieally zero. When $\vec{z}_{e}$ is not zero, $\vec{z}_{0}$ must be adjusted to reduee that error to zero. By using Taylor's theorem we ean express the error veetor $\vec{z}_{e}$ as a power series expanded about $\vec{z}_{0}$. In terms of the eomponents of $z_{e}^{e}$ (i.e., $z_{e i}, i=1,2,3$ ), the following relation is seen to hold

$$
\mathrm{z}_{\mathrm{ei}}\left(\vec{z}_{\mathrm{o}}+\Delta \overrightarrow{\mathrm{z}}_{\mathrm{o}}\right)=\mathrm{z}_{\mathrm{ei}}\left(\vec{z}_{\mathrm{o}}\right)+\left.\sum_{\mathrm{k}=1}^{3} \frac{\partial \mathrm{z}_{\mathrm{ei}}}{\partial \mathrm{z}_{\mathrm{ok}}}\right|_{\mathrm{z}_{\mathrm{o}}} \Delta \mathrm{z}_{\mathrm{ok}}+\cdots \cdot \cdot=0,
$$

where $\Delta \mathrm{Z}_{\mathrm{ok}}$ is the $\mathrm{kth}$ eomponent of $\Delta \vec{Z}_{0}$. In veetor notation $(\mathrm{B}-10)$ beeomes

$$
\vec{z}_{e}\left(\vec{z}_{0}+\Delta \vec{z}_{0}\right)=\vec{z}_{e}\left(\vec{z}_{0}\right)+B \Delta \vec{z}_{0}=0 \text {, }
$$

where terms of higher order than one have been dropped and where $B$ is a $3 \times 3$ matrix defined by

$$
B=\left[\begin{array}{lll}
\frac{\partial z_{e 1}}{\partial z_{o 1}} & \frac{\partial z_{e 1}}{\partial z_{o 2}} & \frac{\partial z_{e 1}}{\partial z_{o 3}} \\
\frac{\partial z_{e 2}}{\partial z_{o 1}} & \frac{\partial z_{e 2}}{\partial z_{o 2}} & \frac{\partial z_{e 2}}{\partial z_{o 3}} \\
\frac{\partial z_{e 3}}{\partial z_{o 1}} & \frac{\partial z_{e 3}}{\partial z_{o 2}} & \frac{\partial z_{e 3}}{\partial z_{o 3}}
\end{array}\right] \text {. }
$$


Then solving Eq. B-11 for $\Delta \vec{Z}_{0}$ results in

$$
\Delta \overrightarrow{\mathrm{Z}}_{0}=\overrightarrow{\mathrm{Z}}_{\mathrm{o}}(\text { new })-\overrightarrow{\mathrm{Z}}_{0}=-\mathrm{B}^{-1} \overrightarrow{\mathrm{Z}}_{\mathrm{e}}\left(\overrightarrow{\mathrm{Z}}_{\mathrm{o}}\right) \text {, }
$$

or

$$
\vec{Z}_{o}(\text { new })=\vec{z}_{o}-B^{-1} \vec{z}_{e}\left(\vec{z}_{o}\right)
$$

Thus Eg. B-14 provides a simple and convenient way of modifying $\vec{Z}_{0}$ given an error $\vec{Z}_{e}$. From a practical perspective $B$ is easily formulated, one column at a time by varying one element of $\vec{z}_{0}$, while holding the other two elements constant. In practice, we found that $\alpha(\theta)$ is so well behaved that most of the time only one (never more than two) iteration of Eq. B-14 is required to arrive at a satisfactory solution. 


\section{APPENDIX C}

\section{INITIAL STATE OF A PRESTRESSED PERFECT RING}

Elementary deformation and loads in an initially perfect ring subsequent to the application of a membrane under uniform tension $T_{0}$ are given in Table $\mathrm{C}-1$ below. Two cases are given. The first corresponds to the membrane being mounted such that the plane of the membrane passes through the frame cross section centroid (or center of twist) of the ring frame (1.e., $h=0$ ) such that no twist will result. The second case corresponds to the situation where the plane of the membrane does not pass through the centroid (i.e., $h \neq 0$ ). The variable $\sigma_{z}$ corresponds to the stress normal to the cross section face as a function of $x$, the distance from the frame neutral axis. The subscripts $\mathbf{N}$ and $B$ correspond to average net compressive and bending components, respectively. Other variables are as previously described.

Table C-1. Initial Stresses and Displacements in an Initially Perfect Frane

\begin{tabular}{|c|c|c|}
\hline & $\begin{array}{c}\text { Perfect Ring } \\
\text { No Twist Case } \\
h=0\end{array}$ & $\begin{array}{c}\text { Perfect Ring } \\
\text { No Twist Case } \\
h \neq 0\end{array}$ \\
\hline Applied Moment Mo & 0 & $-h T_{0}(a / R)$ \\
\hline \multicolumn{3}{|l|}{ Displacements } \\
\hline $\mathbf{v}$ & 0 & 0 \\
\hline$\phi$ & 0 & $-\mathrm{hT}_{\mathrm{o}} \mathrm{Ra}$ \\
\hline$\Psi_{0}$ & $\operatorname{RaT}_{\mathrm{o}}$ & $\underset{\text { RaT }_{0}}{\mathrm{EI}}$ \\
\hline$u_{0}$ & $-\frac{\mathrm{AE}}{\mathrm{A}}$ & $-\overline{\mathrm{AE}}$ \\
\hline Stresses & $-\frac{\mathrm{T}_{\mathrm{o}} \mathrm{a}}{\mathrm{A}}$ & $-\frac{T_{o} a}{A}$ \\
\hline$\sigma_{-0}$ & 0 & $-T_{a}\left(\frac{x h}{-}\right)$ \\
\hline & $\mathrm{T}_{\mathrm{o}} \mathrm{a}$ & $(1 \quad x h)$ \\
\hline$\sigma_{z}$ & $\bar{A}$ & $-T_{0} a\left(\frac{\bar{A}}{\mathrm{~A}}+\frac{-}{\mathrm{I}}\right)$ \\
\hline \multicolumn{3}{|l|}{ Load Resultants } \\
\hline $\mathrm{M}_{\text {yo }}$ & 0 & $\mathrm{hT}_{\mathrm{o}} \mathrm{a}$ \\
\hline $\mathrm{M}_{\mathrm{zo}}$ & 0 & 0 \\
\hline$v_{0}$ & 0 & 0 \\
\hline $\mathrm{N}$ & $\mathrm{T}_{\mathrm{o}} \mathrm{a}$ & $\mathrm{T}_{\mathrm{o}} \mathrm{a}$ \\
\hline
\end{tabular}


The initial conditions in a prestressed initially imperfect ring are more complex than as described above, and the final equilibrium configuration of the frame/membrane assembly (not considering lateral loading) will depend on the attachment and alignment procedure. Though the model presented in the main body of the report can be easily modified to study these effects, these issues will be addressed in a later report. 


\section{SELECTED DISTRIBUTION LIST}

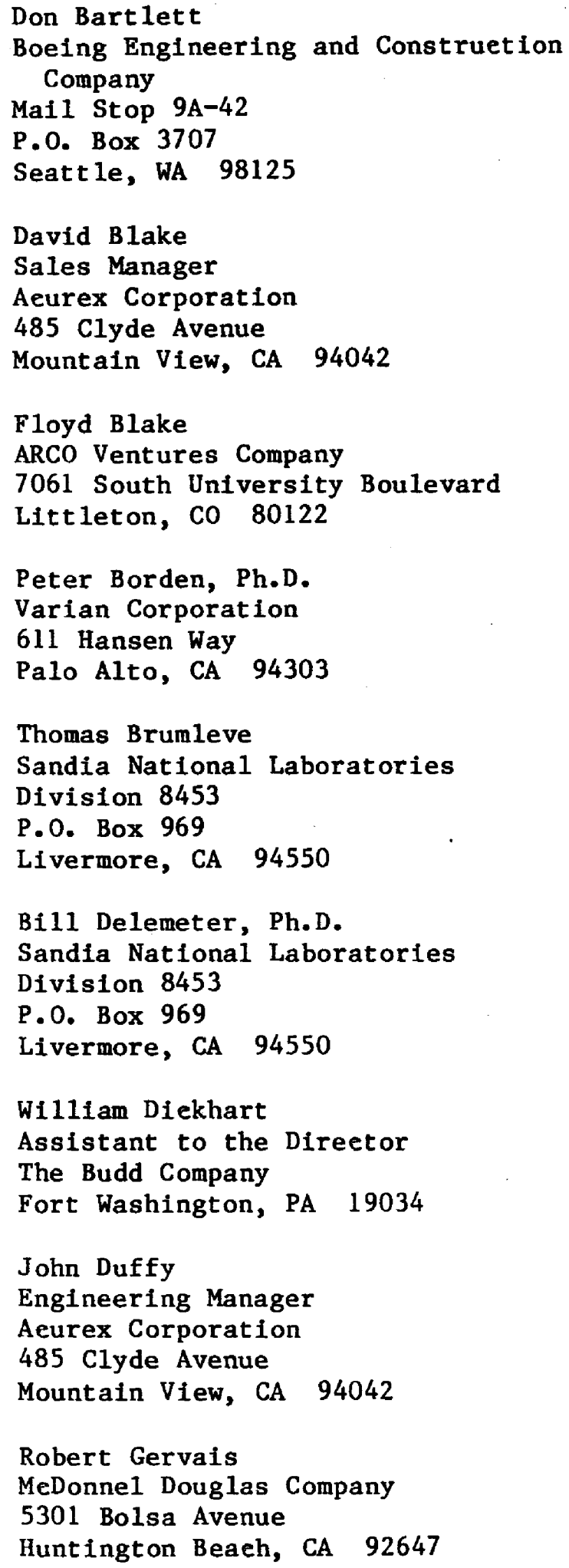

Roger Gillette

Boeing Engineering and Construetion Company

P. 0. Box 3707

Seattle, WA 98125

Wa1ter Hart

Martin Marietta Aerospaee Company

P.0. Box 179

Denver, CO 80201

Jim Leonard, Ph.D.

Sandia National Laboratories

Division 6227

P.0. Box 5800

Albuquerque, $\mathrm{NM} \mathbf{8 7 1 1 5}$

John Lueas, Ph.D.

Jet Propulsion Laboratory

4800 Oak Grove Drive

Pasadena, CA 94103

Monte MeGIaum

LaJet Company

3131 Antilly Road

Abilene, TX 79605

J. T. Pearson, Ph.D.

Purdue University

Meehanieal Engineering Bullding

West Lafayette, IN 47907

Bob Reuter, Ph.D.

Sandia National Laboratories

Division 1523

P. 0. Box 5800

Albuquerque, NM 87115

Jim Rogan, Ph.D.

MeDonne1 Douglas Company

5301 Bolsa Avenue

Huntington Beaeh, CA 92647

Aharon Roy

Head, Solar Power Laboratory

Department of Chemieal Engineering

Ben-Gurion University of Negev

P. 0. Box 653

Beer-Sheva 84105, Israel 
Dan Sallis

Dan-Ka Products

790 Umatilla

Suite 212

Denver, Co 80204

John Schaeffer, Ph.D.

Manager of Projects

Projects Department

Acurex Corporation

485 Clyde Avenue

Mountain View, CA. 94042

Martin Scheve

Department of Energy

CE-314, Room 5H-041

Forrestal Building

1000 Independence Avenue, S.W.

Washington, DC 20585

Kene11 J. Touryan, Ph.D.

Vice President, R\&D

Mt. Moriah Trust

6200 Plateau Drive

Englewood, co 80111

Lee Weinstein

McDonne1 Douglas Company

5301 Bolsa Avenue

Huntington Beach, CA 92647

Tex Wilkins

Department of Energy

CE-314, Room 5H-041

Forrestal Building

1000 Independence Avenue, S.W.

Washington, DC 20585
W1111am Wilson

Sandia National Laboratorles

Division 8453

P.0. Box 969

Livermore, CA 94550

Joan Woodard, Ph. D.

Sandia National Laboratories

Division 8453

P.0. Box 969

Livermore, CA 94550

SOLAR ENERGY RESEARCH INSTITUTE

Dave Benson

Mike Connolly

A1 Czanderna

Gordon Gross

Bim Gupta

Dave Johnson

Gary Jorgensen

Ken 0lsen

Larry Shannon

Dave Stmms

John Thornton

Rick Wood 


\begin{tabular}{|c|c|c|}
\hline $\begin{array}{l}\text { Document Control } \\
\text { Page }\end{array}$ & \begin{tabular}{|l|l|} 
1. SERI Report No. & 2. NTIS Accession No. \\
SERI/TR-253-2101
\end{tabular} & 3. Recipient's Accession No. \\
\hline \multirow{2}{*}{\multicolumn{2}{|c|}{$\begin{array}{l}\text { 4. Title and Subtitle } \\
\text { Analytical Modeling and Structural Response of a } \\
\text { Stretched-Membrane Reflective Module }\end{array}$}} & \multirow[t]{2}{*}{$\begin{array}{r}\text { 5. Publication Date } \\
\text { June } 1984 \\
\end{array}$} \\
\hline & & \\
\hline \multicolumn{2}{|l|}{$\begin{array}{l}\text { 7. Author(s) } \\
\text { L. M. Murphy }\end{array}$} & 8. Performing Organization Rept. No. \\
\hline \multicolumn{2}{|c|}{$\begin{array}{l}\text { 9. Performing Organization Name and Address } \\
\text { Solar Energy Research Institute } \\
1617 \text { Cole Boul evard } \\
\text { Golden, Colorado } 80401\end{array}$} & $\begin{array}{l}\text { 10. Project/Task/Work Unit No. } \\
5102.31 \\
\text { 11. Contract (C) or Grant (G) No. } \\
\text { (C) } \\
\text { (G) }\end{array}$ \\
\hline \multicolumn{2}{|c|}{ 12. Sponsoring Organization Name and Address } & $\begin{array}{l}\text { 13. Type of Report \& Period Covered } \\
\text { Technical Report }\end{array}$ \\
\hline \multicolumn{3}{|l|}{ 15. Supplementary Notes } \\
\hline \multicolumn{3}{|c|}{$\begin{array}{l}\text { 16. Abstract (Limit: } 200 \text { words) } \\
\text { The optical and structural load deformation response behavior of a uniform pres- } \\
\text { sure-loaded stretched-membrane reflective module subject to nonaxisymmetric sup- } \\
\text { port constraints is studied in this report. To aid in the understanding of this } \\
\text { behavior, an idealized analytical model is developed and implemented and pre- } \\
\text { dictions are compared with predictions based on the detailed structural anaiysis } \\
\text { code NASTRAN. Single structural membrane reflector modules are studied in this } \\
\text { analysis. In particular, the interaction of the frame-membrane combination and } \\
\text { variations in membrane pressure loading and tension are studied in detail. Var- } \\
\text { iations in the resulting lateral shear load on the frame, frame lateral support, } \\
\text { and frame twist as a function of distance between the supports are described as } \\
\text { are the resulting optical effects. Results indicate the need to consider the } \\
\text { coupled deformation problem as the lateral frame deformations are amplified by } \\
\text { increasing the membrane tension. The importance of accurately considering the } \\
\text { effects of different membrane attachment approaches is also demonstrated. } \\
\text {. The }\end{array}$} \\
\hline \multicolumn{3}{|c|}{$\begin{array}{l}\text { 17. Document Analysis } \\
\text { a. Descriptors Deformation; Heliostats; Mechanical Structures; Membranes }\end{array}$} \\
\hline \multicolumn{3}{|l|}{ c. UC Categories } \\
\hline \multirow{2}{*}{\multicolumn{2}{|c|}{$\begin{array}{l}\text { 18. Availability Statement } \\
\text { National Technical Information Service } \\
\text { U.S. Department of Commerce } \\
5285 \text { Port Royal Road } \\
\text { Springfield, Virginia } 22161\end{array}$}} & 19. No. of Pages 52 \\
\hline & & $\begin{array}{l}\text { 20. Price } \\
\mathrm{AO4}\end{array}$ \\
\hline
\end{tabular}

